\title{
DO FIRMS SELL FORWARD FOR STRATEGIC REASONS? AN APPLICATION TO THE WHOLESALE MARKET FOR NATURAL GAS
}

\author{
Remco van Eijkel \\ José L. Moraga-González
}


The Public-Private Sector Research Center is a Research Center based at IESE Business School. Its mission is to develop research that analyses the relationships between the private and public sectors primarily in the following areas: regulation and competition, innovation, regional economy and industrial politics and health economics.

Research results are disseminated through publications, conferences and colloquia. These activities are aimed to foster cooperation between the private sector and public administrations, as well as the exchange of ideas and initiatives.

The sponsors of the SP-SP Center are the following:

- Accenture

- Ajuntament de Barcelona

- Caixa Manresa

- Cambra Oficial de Comerç, Indústria i Navegació de Barcelona

- Consell de l'Audiovisual de Catalunya

- Departament d' Economia i Finances de la Generalitat de Catalunya

- Departament d' Innovació, Universitats i Empresa de la Generalitat de Catalunya

- Diputació de Barcelona

- Endesa

- Fundació AGBAR

- Garrigues

- Mediapro

- Microsoft

- Sanofi Aventis

- ATM, FGC y TMB

The contents of this publication reflect the conclusions and findings of the individual authors, and not the opinions of the Center's sponsors. 


\title{
Do Firms Sell Forward for Strategic Reasons? An Application to the Wholesale Market for Natural Gas*
}

\author{
Remco van Eijkel ${ }^{\dagger} \quad$ José L. Moraga-González ${ }^{\ddagger}$
}

June 2010

\begin{abstract}
Building on a model of the interaction of risk-averse firms that compete in forward and spot markets, we develop an empirical strategy to test whether oligopolistic firms use forward contracts for strategic motives, for risk-hedging, or for both. An increase in the number of players weakens the incentives to sell forward for risk-hedging reasons. However, if strategic motives are also relevant, then an increase in the number of players strengthens the incentives to sell forward. This difference provides the analyst with a way to identify whether strategic considerations are important at motivating firms to sell forward. Using data from the Dutch wholesale market for natural gas where we observe the number of players, spot and forward sales, and churn rates, we find evidence that strategic reasons play an important role at explaining the observed firms' (inverse) hedge ratios. In addition, the data lend support to the existence of a learning effect by wholesalers.
\end{abstract}

Keywords: market power, risk-hedging, forward contracts, spot market, over-thecounter trade, market transparency, churn rates.

JEL Classification: D43, L13, G13, L95

*We thank Rob Alessie, Paul Bekker, Ramón Caminal, Giulio Federico, Niels-Henrik von der Fehr, Christian von Hirschhausen, Sjaak Hurkens, Matilde Machado, Allard van der Made, Ruud van der Meer, Anne Neumann, François Salanié, Zsolt Sandor, Xavier Vives and Bert Willems for useful comments. The paper has also benefited from presentations at Humboldt University Berlin, University of Cambridge, University Carlos III Madrid, Institute of Economic Analysis (Barcelona), the IIOC 2009 (Boston), ESEM 2009 (Barcelona), EARIE 2009 (Ljubljana) and at the 2010 IDEI conference on Energy Markets (Toulouse). We are also indebted to Mark Hobbelink and Sybren de Jong from Gas Transport Services B.V. for providing us with some of the necessary data, and to Chenlang Tang (Tommy) for his excellent research assistance.

${ }^{\dagger}$ Dep. of Economics, Econometrics and Finance, University of Groningen. E-mail: r.van.eijkel@rug.nl

${ }_{\ddagger}^{\ddagger}$ ICREA, IESE Business School and University of Groningen. E-mail: jose.l.moraga@gmail.com. 


\section{Introduction}

Electricity and gas industries used to consist of vertically integrated monopolies, state-owned or not, operating under regulatory constraints. In each country or region there was a single monopolistic importer in place, which typically owned the transmission network and either sold directly to consumers or to downstream distribution monopolies. One-to-one negotiations was the standard of trade throughout the value chain and the different parties were typically subject to long-lasting contractual relationships.

Short- and long-run efficiency considerations have led energy policy makers worldwide to gradually restructure energy markets. A key feature has been the vertical separation of production and transportation activities. This separation has enabled the creation of spot commodity markets. The Pool in the UK, ISO in California, the real-time PJM market in Pennsylvania, New Jersey and Maryland, ERCOT in Texas, EPEXSPOT in Austria, France, Germany and Switzerland are examples in electricity; NBP in the UK, the Henry Hub in the US, the Zeebrugge Hub in Belgium and TTF in The Netherlands are examples in natural gas.

The 2000-2001 electricity crisis in California has revealed that the combined prevalence of price risks and market power in energy markets may have fatal consequences when riskhedging mechanisms are absent (Bushnell, 2004). As a consequence, in nowadays restructuring, it is widely held that spot markets must necessarily be complemented with forward markets (Ausubel and Cramton, 2009). In an attempt to aid firms to contract forward, platforms have been created where property rights can more easily be transferred among the participants. ${ }^{1}$ In addition, in some markets we have witnessed the creation of futures exchanges. Examples of markets for electricity futures are CALPX in California and EEX Power Derivatives in Austria, France, Germany and Switzerland; ENDEX runs a market for natural gas futures in The Netherlands, as well as markets for UK and Dutch electricity futures.

Facilitating forward transactions has the potential to deliver social benefits on two accounts. First, forward markets address the need of a firm to hedge risks. Forward contracts typically specify fixed delivery prices so risk-averse market participants can mitigate their exposure to price shocks in the spot market by acquiring a portfolio of futures. Central results in the literature relate to the decisions of a competitive risk-averse firm facing price uncertainty (see e.g Baron, 1970; Holthausen, 1979; and Sandmo, 1971). In the absence of a futures market, this type of firm turns out to restrict its output relative to what the firm would produce under certainty. The opening of a forward market restores the level of output that would prevail if uncertainty were removed.

\footnotetext{
${ }^{1}$ One development in natural gas has been the creation of virtual hubs, for example the NBP and TTF, as opposed to the more traditional physical hubs, like the Henry Hub and the Zeebrugge Hub. A physical hub is a location where several pipelines come together, so that total physical throughput is delivered at this point. By contrast, virtual hubs contain several entry and exit points that are interconnected, which implies that not all the gas traded has to flow through a single point in the pipeline system.
} 
Forward markets can deliver further social benefits in situations where firms wish to sell forward for strategic reasons. In their influential paper, Allaz and Vila (1993) show that forward contracts confer competitive advantages to Cournot firms so, even when there is no uncertainty at all about future market conditions, firms have incentives to engage in forward trading. By selling futures contracts at a pre-specified price, a firm ends up attaching a lower value to a high spot market price. As a result, a firm that sells forward is indirectly committing to an aggressive behavior in the spot market. This raises firm profitability, since competitors respond by adopting a compliant spot market strategy. Selling forward exhibits however the characteristics of a prisoner's dilemma. Because every seller has incentives to sell (part of) its output forward, the resulting equilibrium aggregate production is higher (and the price lower) than in the absence of a futures market. ${ }^{2}$

To the best of our knowledge, whether the forward market institution by itself is successful on these two fronts at a time is not well understood yet. One obvious reason for this lack of knowledge is that a great deal of the contracts we have observed in gas and electricity markets has not been dictated by market forces but imposed by the regulators in the form of gas release programs or vesting electricity contracts (Borenstein, 2002; Wolfram, 1999). A second reason is that disentangling the two rationales motivating firms to sell forward -strategic commitment and risk-hedging- from the field data is, at least, methodologically challenging; in addition, it requires a wealth of data on forward transactions. In this paper we propose an empirical strategy to separate the various incentives behind the contract cover of a firm and we apply it to the Dutch natural gas market.

Our methodology to test whether firms use forward contracts for strategic reasons and/or for risk-hedging motives builds on the idea that commitment has value only if it is (imperfectly) observable (Allaz and Vila, 1993; Kao and Hughes, 1997). Inspired from this idea, we develop a model of the interaction of asymmetric risk-averse firms that compete in a forward market before they set quantities in a spot market. The key aspect of the modelling is that it introduces the extent to which forward positions are observable (or correctly inferred from the forward price) as a structural parameter that can be estimated provided there is variation in the number of participating firms.

In real-world energy markets, it is reasonable to assume that rivals' forward positions may be difficult to observe. First, where they exist, markets for natural gas and electricity futures are designed to be anonymous and this anonymity puts impediments for the forward positions of each individual rival firm to be observed with a reasonable precision. Second, even if in principle observation of the forward price may help firms to infer the rivals' aggregate forward position, the process of (forward) price discovery is far from simple. This is because some (or all) of the transactions in these markets are made over the counter (OTC) as organized exchanges are often bypassed by the traders or totally lacking. OTC markets are relatively non-transparent and price indices for these markets, typically provided by broker associations of by specialized agencies, are based on a limited pool of recent transactions.

\footnotetext{
${ }^{2}$ The model of Allaz and Vila has been adapted to suit the particular organization of power markets in the UK by von der Fehr and Harbord (1992), Powell (1993), Newbery (1998) and Green (1999).
} 
By construction, price indices are complex statistics so it is unclear how much a participant in the market can learn about rivals' deviations from equilibrium play. Even if centralized futures markets are more transparent, seen that arbitrage opportunities across the exchanges and the OTC markets are not always fully exhausted, the existence of conflicting price signals (as the law of one price fails) further troubles the quality of the inferences market participants can make (see e.g. Anderson, Hu and Winchester, 2007; Bushnell, 2007).

Our model bridges between the extreme cases of full transparency (perfect observability of rivals' forward positions) and complete opacity of the forward market (no observability at all). By doing so, the model gains in flexibility to fit the data and helps us understand the extent to which the forward market provides the players with commitment possibilities.

We show how to estimate the model using data on total sales, forward sales, churn ratios and numbers of producers and wholesalers. Identification of the key parameter requires variation in the number of active wholesale firms. In our data this variation comes from entry of new players in the market but in other studies the analyst could exploit variation in the number of producers and wholesalers across regional/separated markets. The empirical test exploits the effect that changes in the number of players has on the so-called inverse hedge ratio -defined as the total-to-forward-sales ratio. ${ }^{3}$ Interestingly, for the linear model this ratio is independent of demand intercept and marginal cost so firms with similar aversion to risk hedge in the same way no matter their marginal costs of production and the state of the demand.

In a nutshell, the identification arguments are as follows. The incentives of a firm to trade forward are shaped by three forces. The first two, the risk-hedging effect and the strategic effect, are pro-contracts. The third is a price effect that arises because offering forward contracts lowers the spot price and, by arbitrage, the forward price too. This price effect actually puts a downward pressure on firm's (expected) profits and therefore makes forward contracting less attractive.

When the forward market is relatively opaque so that players have a difficult time to infer deviations from equilibrium play, the strategic effect is hardly present and the contract cover of a firm is the outcome of trading off the risk-hedging effect against the price effect. In that situation, as the number of competitors rises, the residual demand of an individual firm becomes less susceptible to demand shocks. Therefore, the incentive to hedge becomes weaker if more suppliers enter the market. The price effect, by contrast, stays constant if the number of suppliers in the market increases. As a result, by virtue of the first force, the inverse hedge ratio increases in the number of competitors.

By contrast, if the forward market is relatively transparent so that price and/or rival firms' forward positions are regularly and precisely observed, in addition to the risk-hedging and the price effects, the strategic effect plays a significant role. This strategic effect turns out to be stronger as more players are around. This is because the (marginal) gains from affecting

\footnotetext{
${ }^{3}$ To be precise, inverse hedge ratio $=($ spot sales + forward sales $) /$ forward sales .
} 
the rivals' spot market strategy rise with the number of competitors. We show that the strategic effect may have a dominating influence in which case inverse hedge ratios turn out to be decreasing in the number of firms. This different impact of the number of firms on inverse hedge ratios in case forward positions can correctly be forecasted by the market participants constitutes the source of identification of the strategic effect.

We estimate the model using data from the Dutch wholesale market for natural gas. In contrast to restructured markets elsewhere, the Dutch natural gas market is one where futures contracts have not been forced upon the producers and wholesalers by the regulator. This is important because otherwise it is difficult to learn whether the market by itself provides the players with the necessary hedging and commitment opportunities. Our data set consists of a fairly large fraction of all (forward, spot and speculative) trades conducted at the Dutch gas hub Title Transfer Facility (TTF), from April 2003 until June 2008. ${ }^{4}$ We use information on churn rates (i.e. information on the fraction of speculative trades) to construct the inverse hedge ratios concerning the actual deliveries of natural gas. The model imposes a restriction on the inverse hedge ratios which, using variation on number of producers and wholesalers, can be estimated. The main empirical finding is that strategic considerations cannot be discarded as an explanation for the observed (inverse) hedge ratios. Seen under the light that most of the forward transactions occur OTC and therefore the forward market we study can initially be regarded as relatively non-transparent, we think this is an important result. Moreover, we document a learning effect, which we relate to the rapid development of (gross and net) volumes traded at the TTF. By contrast, we do not find significant evidence that risk-hedging is important in this market. We discuss the possible explanations for this result later.

Our paper contributes to the literature that studies forward contracting of (essentially) nonstorable goods. ${ }^{5}$ Allaz (1992) and Allaz and Vila (1993) show that not only risk-hedging is important for firms to sell contracts in Cournot markets. Kao and Hughes (1997) discuss the role of the observability-of-forward-positions assumption. Mahenc and Salanié (2006) demonstrate that selling forward may have anticompetitive effects when firms compete in prices. Ferreira (2003) also encounters anticompetitive effects when firms are able to sell in a futures market at infinitely many moments prior to the opening of the spot market. ${ }^{6}$ Our model extends previous work by examining an $n$-firm game with risk-averse players that are heterogeneous in their marginal costs of production and in their aversion to risk. We explore two variants of the model, one where firms observe demand shocks before the spot market opens, and one where the spot market remains uncertain. Although we cannot find closed-form solutions for the forward and spot sales of an individual firm, we derive its

\footnotetext{
${ }^{4}$ The TTF is a virtual market place that offers market participants the possibility to buy and sell gas that is already injected into the Dutch gas transmission grid, or for which transportation capacity is already booked.

${ }^{5}$ Natural gas can be stored more easily than electricity but the costs of doing so are relatively high, so that for its most part production, delivery and consumption take place contemporaneously.

${ }^{6}$ See also Newbery (1998) and Green (1999), who study models where firms compete in the spot market using supply schedules. These papers show that, owing to the multiplicity of equilibria in supply functions, the optimal contract cover of a firm is intimately linked to the spot market equilibrium actually played.
} 
equilibrium (mean) inverse hedge ratio. These ratios turn out to have similar properties, the most important for our purposes that they fall in the number of players when the forward market is sufficiently transparent.

Our paper also adds to a growing empirical literature on the effects of forward contracting on spot market strategies and energy market outcomes (Green, 1999; Wolak, 2000; Fabra and Toro, 2005; Hortaçsu and Puller, 2008; Bushnell, Mansur and Saravia, 2008). These papers have focused on electricity markets where forward contracts have often been imposed by regulators and can therefore be considered exogenous to the equilibrium process. By contrast, we deal with a market where forward contracts are endogenous. Our results lend support to the idea that the market may by itself provide the necessary incentives to the firms to engage in a healthy amount of forward contracting.

There is also work that has focused on forward and spot price differences in energy markets. Longstaff and Wang (2004) document significant risk-premia in electricity forward prices. Bessembinder and Lemmon (2006) derive the equilibrium forward risk premium in a competitive model of the interaction of producers and retailers in the absence of speculators. Our paper differs from theirs in that our producers have market power. This allows us to address the issue of whether they sell futures contracts to hedge or to gain market power in the spot market. ${ }^{7}$

The rest of the paper is organized as follows. The next section presents a two-period model of competition. In the first period, the forward market opens and firms sell futures contracts. In the second period, the spot market opens, firms sell quantities and delivery of all contracted and spot quantities takes places. This section also presents the main empirical prediction of our model. We take it to the data in Section 4. Before that, Section 3 discusses in some detail the institutions of the Dutch wholesale gas market. The paper closes with a discussion of the main results, some extensions and variations of the basic model and some concluding remarks.

\section{$2 \quad$ A model of forward and spot contracting}

Consider an oligopolistic market with $n$ asymmetric risk-averse firms selling a homogeneous good. Firms are asymmetric on two accounts: they differ in their degree of risk-aversion and have different marginal costs of production. Firms can sell output in the spot market;

\footnotetext{
${ }^{7}$ An alternative, and complementary, approach to address this issue is to use controlled experiments. In a recent paper, Brandts, Pezanis-Christou and Schram (2008) set up laboratory experiments to study the efficiency effects brought about by the possibility of forward contracting. Working with deterministic demand and cost parameters, risk-hedging can be, if not fully eliminated, at least significantly reduced. Brandts et al. observe that significant price decreases and efficiency gains are obtained compared to the case in which only spot market trading is possible. Additional experimental evidence on the pro-competitive effects of futures contracts is provided by Coq and Orzen (2006). Ferreira, Kujal and Rassenti (2009) challenge this view and present experimental evidence to suggest that forward contracts make collusion more likely. Their results are in line with Liski and Montero (2006).
} 
in addition, they can also sell (or buy) the good in a forward market. ${ }^{8}$ Let $s_{i}$ and $x_{i}$ be, respectively, firm $i$ 's total spot and forward market sales; the total output firm $i$ supplies on the market will be denoted $q_{i}\left(=s_{i}+x_{i}\right)$. The marginal cost of production of a firm $i$ is denoted $c_{i} \cdot{ }^{9}$

We assume that market demand is random and given by the linear-normal specification

$$
p=a-b Q+\epsilon, \epsilon \sim N\left(0, \sigma^{2}\right)
$$

where $Q=\sum_{i=1}^{n} q_{i}$ denotes the aggregate output delivered to consumers and $\epsilon$ is a zeromean random shock normally distributed with standard deviation $\sigma .{ }^{10}$ We assume that the realization of $\epsilon$ is observed when the spot market opens. ${ }^{11}$ At that stage, a firm $i$ chooses its spot sales $s_{i}$ to maximize its spot market profits. ${ }^{12}$

At the forward market stage, by contrast, firms are uncertain about the price that will prevail in the market. As a result, at that stage, a firm views its monetary flow of profits as a random variable. We assume firms are risk averse and have constant absolute risk aversion (CARA) utility functions. Let $\pi_{i}$ be the realized (forward and spot) monetary profits of a firm $i$. The utility function of a firm $i$ is $u\left(\pi_{i}\right)=-e^{-\rho_{i} \pi_{i}}$, where $\rho_{i}>0$ denotes firm $i$ 's degree of risk aversion. ${ }^{13}$ Denote by $F\left(\pi_{i}\right)$ the distribution of the monetary profits $\pi_{i}$ of a firm $i$. (Note that this distribution is endogenous and will be determined later.) Then a firm

\footnotetext{
${ }^{8}$ Forward contracts are contracts traded in the OTC market, while futures contracts change hands in centralized exchanges. Since both types of contracts serve the same objectives, we use them interchangeably throughout the paper.

${ }^{9}$ In the natural gas industry, on the supply side of the market we typically encounter producers and wholesalers. The constant marginal cost assumption is probably a good approximation for the costs of extraction and shipping incurred by producers. European wholesalers typically import gas from producing countries such as Norway and Russia. Wholesalers have long-term take-or-pay contracts with foreign producers. Takeor-pay contracts stipulate that the buyer pays for a pre-specified minimum amount of gas, irrespective of whether the gas is actually taken (Masten and Crocker, 1985). Take-or-pay contracts also include a variety of (daily and yearly) flexibility clauses (Asche et al., 2002; IEA, 2002). These clauses provide wholesalers with the necessary flexibility to adjust supply to demand shocks. Take-or-pay contracts are typically indexed to the oil price so the constant marginal cost assumption is also reasonable. Moreover, because wholesalers book import capacity assuming extreme weather conditions, transport capacity is typically not binding. Pipelines also allow for line-pack, that is, for the increase in the amount of gas the system can carry by temporarily raising its pressure.

${ }^{10}$ Even though producers and wholesalers may differ in that the latter face both price and cost risk, in what follows we will not make a distinction between their economic problems. Note also that in our linear model randomness of the demand is equivalent to randomness on the marginal cost.

${ }^{11}$ This assumption is not necessary. It reflects the idea that firms are typically well informed about the state of the demand when the spot market opens and use such a market to balance their portfolios. Later in Section 4 we develop the case in which at the spot market stage firms are still uncertain about the realization of $\epsilon$. The main theoretical insights of the model generalize to such case (see Proposition 2); in addition, our estimates do not depend on this modeling choice (see Tables 5, 6 and 7).

${ }^{12}$ In our application, the demand side of the market is made of domestic retailers and exporting shippers. We do not model risk aversion on the demand side because retail prices in the Netherlands and the surrounding countries are non-regulated and a great deal of the retail contracts have variable prices (see e.g. von der Fehr and Hansen, 2010).

${ }^{13}$ The case of risk-neutrality obtains when $\rho_{i} \rightarrow 0$ for all $i$.
} 
$i$ will choose its forward sales $x_{i}$ to maximize its expected utility:

$$
E\left[u\left(\pi_{i}\right)\right]=\int-e^{-\rho_{i} \pi_{i}} d F\left(\pi_{i}\right)
$$

For simplicity, future spot market profits are not discounted. ${ }^{14}$

Next, and central to our paper, we assume that whether firms observe each other's forward positions is uncertain. To model this idea, we introduce a Bernoulli random variable, denoted $I$, with parameter $\gamma$. If $I=1$ forward positions become observable to the players and then we get the standard Allaz and Vila (1993) setting. By contrast, if $I=0$ we obtain the case of unobservable forward trading, as discussed by Kao and Hughes (1997). ${ }^{15}$ The parameter $\gamma$ can then be interpreted as the degree of transparency of the forward market. As mentioned in the Introduction, another, and perhaps more compelling, interpretation of this parameter is that it reflects the ability of firms to infer deviations from the equilibrium path by looking at forward price changes. ${ }^{16}$ One objective of the paper is to estimate the Bernoulli parameter $\gamma$.

We further assume there is a fringe of outside speculators. These traders, which are assumed to be risk-neutral, do not have transmission capacity rights so they cannot physically deliver the commodity to the final customers. Speculators compete à la Bertrand for the quantities offered in the forward market. We shall also assume that pure financial traders observe sellers' deviations from the equilibrium path. This assumption is based on the idea that speculators take positions that increase their exposure to risk in an attempt to (weakly) increase their wealth. As such, they have perhaps the strongest incentives to follow upon the forward market developments. For the model at hand, this assumption implies that a strong version of arbitrage (off and on the equilibrium path) between forward and spot markets holds. ${ }^{17}$

\footnotetext{
${ }^{14}$ As it will become clear later, monetary profits are not normally distributed so maximizing (2) is not equivalent to maximizing the corresponding mean-variance specification. We also worked with mean-variance utility functions and the results obtained were similar.

${ }^{15}$ We model imperfect observability by assuming that firms either observe the (correct) forward price or they miss it altogether. An alternative way to model imperfect observability is by assuming that firms may observe forward prices that are wrong. In that case Bagwell (1995) shows that the value of commitment is fully destroyed; van Damme and Hurkens (1997) show that Bagwell's striking result relies on an unnecessary restriction to pure strategies.

${ }^{16}$ Forward markets are to some extent opaque. Many transactions occur over the counter and therefore are invisible to market participants. Forward price indices are published by brokers and specialized information agencies. Firms may be able to infer rivals' forward positions upon observation of those indices but the question is how well. We can think of $\gamma$ as the fraction of times the firms are able to forecast how deviations from the equilibrium forward sales will affect the spot market price. In this sense, firms can be seen as been ignorant, or naive, $1-\gamma$ of the times.

${ }^{17}$ Ferreira (2006) studies the role of the observability assumption at length. He argues that it is hard to reconcile the assumption that firms are not informed of the rivals' forward positions with the assumption that speculators observe deviations at the forward stage. As mentioned earlier, in the real-world forecasting quantities sold upon observing forward price indices is far from trivial, specially if firms are heterogeneous. Speculators are not gamblers but highly specialized investors whose profit critically depends on the quality of the forecasts they make.
} 
The timing of the game is as follows. In the first stage, firms put quantities in the forward market. Then the Bernoulli variable $I$ is realized and forward positions become observable or not. Next, firms learn the demand shock $\epsilon$. Finally, firms compete in quantities in the spot market and total sales are delivered. We now solve the game by backward induction.

\section{$2.1 \quad$ Spot market stage}

At the time the spot market opens, demand is certain and firm $i$ chooses its spot sales $s_{i}$ to maximize its spot market profits:

$$
\pi_{i}^{s}=\left(p-c_{i}\right) s_{i}
$$

where $p$ is the realized spot market price given in (1). For this, a firm $i$ takes the spot market strategies and, when observed, the forward positions of the rival firms as given. In case of an opaque forward market, firm $i$ makes a conjecture about the forward sales of its competitors.

18 The spot market equilibrium turns out to be in linear strategies. Putting the linearity of the strategies up front, we write the spot market strategy of a firm $i$ as:

$$
s_{i}=A_{i}+B_{i} \epsilon, i=1, \ldots, n .
$$

When $I=1$, which occurs with probability $\gamma$, firms observe each other forward positions. In that case, the realization of the spot market price can be written as:

$$
p=a+\left(1-b \sum_{j \neq i}^{n} B_{j}\right) \epsilon-b x_{i}-b \sum_{j \neq i}^{n} x_{j}-b s_{i}-b \sum_{j \neq i}^{n} A_{j}
$$

where $\sum_{j \neq 1}^{n} x_{j}$ is the sum of the actual forward positions of firm i's competitors. Profit maximization at the spot market stage gives

$$
s_{i}=\frac{1}{2 b}\left(a+\left(1-b \sum_{j \neq i}^{n} B_{j}\right) \epsilon-c_{i}-b x_{i}-b \sum_{j \neq i}^{n} x_{j}-b \sum_{j \neq i}^{n} A_{j}\right)
$$

Using (4), we can solve for $A_{i}$ and $B_{i}$ :

$$
A_{i}=\frac{a+\sum_{j \neq i}^{n} c_{j}-n c_{i}-b x_{i}-b \sum_{j \neq i}^{n} x_{j}}{b(n+1)}, B_{i}=\frac{1}{b(n+1)}
$$

Therefore, conditional on the forward positions being observable, the equilibrium spot market output of firm $i$ equals:

$$
s_{i}^{I=1}=\frac{a+\epsilon+\sum_{j \neq i}^{n} c_{j}-n c_{i}-b x_{i}-b \sum_{j \neq i}^{n} x_{j}}{b(n+1)}
$$

and the equilibrium spot market price equals:

$$
p^{I=1}=\frac{a+\epsilon+\sum_{i}^{n} c_{i}-b x_{i}-b \sum_{j \neq i}^{n} x_{j}}{n+1} .
$$

\footnotetext{
${ }^{18}$ We require the conjectures to be correct in equilibrium.
} 
The conditional reduced-form profits are then given by:

$$
\pi_{i}^{I=1}=b\left(s_{i}^{I=1}\right)^{2}+\left(f-c_{i}\right) x_{i}
$$

where $f$ denotes the forward price.

When $I=0$, which occurs with probability $1-\gamma$, firms do not observe each other's actions in the forward market. This implies that deviations of a firm $i$ from the equilibrium path go undetected by the rival players. In that case, the price in the spot market is given by:

$$
p=a+\left(1-b \sum_{j \neq i}^{n} B_{j}\right) \epsilon-b x_{i}-b \sum_{j \neq 1}^{n} \hat{x}_{j}-b s_{i}-b \sum_{j \neq i}^{n} A_{j}
$$

where $\sum_{j \neq i}^{n} \hat{x}_{j}$ is firm i's conjecture about the rivals' aggregate forward position. The first order condition (FOC) for the spot market stage is given by:

$$
s_{i}=\frac{1}{2 b}\left(a+\left(1-b \sum_{j \neq i}^{n} B_{j}\right) \epsilon-c_{i}-b x_{i}-b \sum_{j \neq i}^{n} \hat{x}_{j}-b \sum_{j \neq i}^{n} A_{j}\right)
$$

Because firm $i$ does not observe deviations from the conjectured (equilibrium) forward sales of the rival firms, its spot market strategy is only affected by (a change in) its own forward position. We can solve for $\sum_{j \neq i}^{n} A_{j}$ and $\sum_{j \neq i}^{n} B_{j}$ :

$$
\sum_{j \neq i}^{n} A_{j}=\frac{(n-1)\left(a+c_{i}-b \hat{x}_{i}-b \sum_{j \neq i}^{n} \hat{x_{j}}\right)-2 \sum_{j \neq i}^{n} c_{j}}{b(n+1)}, \sum_{j \neq i}^{n} B_{j}=\frac{n-1}{b(n+1)}
$$

As a result, conditional on the forward positions not being observed, the spot market sales of firm $i$ are:

$$
s_{i}^{I=0}=\frac{a+\epsilon+\sum_{j \neq i}^{n} c_{j}+b(n-1) \hat{x}_{i} / 2-n c_{i}-b(n+1) x_{i} / 2-b \sum_{j \neq i}^{n} \hat{x}_{j}}{b(n+1)}
$$

and the realized market price:

$$
p^{I=0}=\frac{a+\epsilon+c_{i}+\sum_{j \neq i}^{n} c_{j}+b(n-1) / 2 \hat{x}_{i}-b(n+1) x_{i} / 2-b \sum_{j \neq i}^{n} \hat{x}_{j}}{n+1}
$$

The conditional profit of firm $i$ 's equals:

$$
\pi_{i}^{I=0}=b\left(s_{i}^{I=0}\right)^{2}+\left(f-c_{i}\right) x_{i} .
$$

\subsection{Forward market stage}

At the forward market stage, firms sell (or buy) part of their total output in the futures market to maximize their expected utility. ${ }^{19}$ Note that $u\left(\pi_{i}\right)=I u\left(\pi_{i}^{I=1}\right)+(1-I) u\left(\pi_{i}^{I=0}\right)$.

\footnotetext{
${ }^{19}$ We do not a priori restrict firms' level of forward trading to be positive. However, in equilibrium each firm will sell a non-negative amount in the forward market.
} 
Using the expressions for the conditional profits derived above, the expected utility of firm $i$ is thus given by:

$$
E\left[u\left(\pi_{i}\right)\right]=-\gamma \int e^{-\rho_{i} \pi_{i}^{I=1}} f(\epsilon) d \epsilon-(1-\gamma) \int e^{-\rho_{i} \pi_{i}^{I=0}} f(\epsilon) d \epsilon
$$

where $f(\epsilon)$ is the density function of the normal distribution with zero mean and variance given by $\sigma^{2}$.

A firm $i$ picks its amount of forward sales $x_{i}$ to maximize its expected utility. It is instructive to write the FOC as follows:

$$
\begin{aligned}
& \gamma \int \rho_{i} e^{-\rho_{i} \pi_{i}^{I=1}}\left(\frac{\partial \pi_{i}^{I=1}}{\partial x_{i}}+\sum_{j=1}^{n} \frac{\partial \pi_{i}^{I=1}}{\partial s_{j}} \frac{\partial s_{j}}{\partial x_{i}}\right) f(\epsilon) d \epsilon+ \\
& (1-\gamma) \int \rho_{i} e^{-\rho_{i} \pi_{i}^{I=0}}\left(\frac{\partial \pi_{i}^{I=0}}{\partial x_{i}}+\frac{\partial \pi_{i}^{I=0}}{\partial s_{i}} \frac{\partial s_{i}}{\partial x_{i}}\right) f(\epsilon) d \epsilon=0
\end{aligned}
$$

In equilibrium $\hat{x}_{i}=x_{i}$ for all $i$ and so is $\pi_{i}^{I=1}=\pi_{i}^{I=0}=\pi_{i}$ and $\partial \pi_{i}^{I=1} / \partial x_{i}=\partial \pi_{i}^{I=0} / \partial x_{i}=$ $\partial \pi_{i} / \partial x_{i}$; therefore, this FOC can more compactly be written as follows:

$$
\begin{gathered}
\int \rho_{i} e^{-\rho_{i} \pi_{i}}\left(\frac{\partial \pi_{i}}{\partial x_{i}}+(1-\gamma) \frac{\partial \pi_{i}}{\partial s_{i}} \frac{\partial s_{i}}{\partial x_{i}}+\gamma \sum_{j=1}^{n} \frac{\partial \pi_{i}}{\partial s_{j}} \frac{\partial s_{j}}{\partial x_{i}}\right) f(\epsilon) d \epsilon= \\
\int \rho_{i} e^{-\rho_{i} \pi_{i}}\left(-b x_{i}+(1-\gamma) \frac{b x_{i}}{2}+\gamma \frac{b x_{i}+(n-1) b\left(s_{0}+x_{i}\right)}{n+1}-\frac{\epsilon}{n+1}+\gamma \frac{(n-1) \epsilon}{(n+1)^{2}}\right) f(\epsilon) d \epsilon= \\
\int \rho_{i} e^{-\rho_{i} \pi_{i}}\left(-\frac{b x_{i}}{2}-\frac{\epsilon}{n+1}+\gamma \frac{b(n-1)\left(x_{i} / 2+s_{0}\right)}{(n+1)}+\gamma \frac{(n-1) \epsilon}{(n+1)^{2}}\right) f(\epsilon) d \epsilon=0
\end{gathered}
$$

where

$$
s_{0}=\frac{a+\sum_{j \neq i} c_{j}-n c_{i}-b x_{i}+b \sum_{j \neq i} x_{j}}{b(n+1)}
$$

The first term of this equation (after the integral sign) represents marginal utility from (monetary) profit, while the term between parentheses is the marginal monetary profit from selling futures contracts. A firm $i$ chooses its amount of futures $x_{i}$ to make the expected value of the product of marginal utility and marginal monetary profit equal to zero.

The incentives of a firm $i$ to sell forward are shaped by three forces. There is a risk-hedging effect, a strategic effect and a price effect. The first two forces are pro-contracts; the third one dampens the incentives to sell futures. These three forces can actually be seen after taking a closer look at equation (19). To see them more clearly, it is useful to consider the two extreme cases of complete opacity $(\gamma=0)$ and complete transparency $(\gamma=1)$ of the forward market. 
When forward positions cannot be observed by the rivals the strategic effect is absent and equation (19) simplifies to

$$
\int \rho_{i} e^{-\rho_{i} \pi_{i}}\left(\frac{\partial \pi_{i}}{\partial x_{i}}+\frac{\partial \pi_{i}}{\partial s_{i}} \frac{\partial s_{i}}{\partial x_{i}}\right) f(\epsilon) d \epsilon=\int \rho_{i} e^{-\rho_{i} \pi_{i}}\left(-\frac{b x_{i}}{2}-\frac{\epsilon}{n+1}\right) f(\epsilon) d \epsilon=0
$$

In parenthesis we see the direct effect of selling forward on a firm's monetary profits, along with a second effect that goes via its own spot market strategy, $s_{i}$. This joint effect is clearly negative and has a deterministic component and a random component. The deterministic component, $-b x_{i} / 2$, constitutes a negative price effect that is independent of the number of firms. A firm that puts one unit more in the forward market cuts its spot sales by half a unit (see equation (14)), so its total sales increase. This results in a fall in the spot market price, which is anticipated by the speculators and therefore the forward price falls too. ${ }^{20}$ This own price effect dampens the incentives to put futures in the market, which explains why a risk-neutral monopolist would choose not to engage in forward contracting at all (see Tirole, 2006, p. 216-17). Since this effect is always negative no matter the number of firms, it is also true that a risk-neutral oligopolist would opt out of the contract market (Hughes and Kao, 1997).

The random component explains the risk-hedging motive. Note that a firm that increases its contract cover away from zero lowers its exposure to demand shocks by $\epsilon /(n+1)$ (see equation (20)). This random component is negatively correlated with $\epsilon$ and so is the marginal utility from monetary profit (since profit increases in $\epsilon$ and the utility function is concave). As a result, the covariance between marginal utility and marginal profit is positive, giving rise to the risk-hedging incentive of selling forward contracts. When contracts cannot be observed by the market participants, the optimal contract cover of a firm $i$ is the outcome of trading off the (positive) risk-hedging motive against the (negative) price effect.

When forward positions are easily observable by the firms, or can easily be inferred from the forward price, $\gamma=1$ and equation (19) simplifies to

$$
\int \rho_{i} e^{-\rho_{i} \pi_{i}}\left(-\frac{b x_{i}}{2}-\frac{\epsilon}{(n+1)}+\frac{b(n-1)}{(n+1)}\left(x_{i} / 2+s_{0}\right)+\frac{(n-1) \epsilon}{(n+1)^{2}}\right) f(\epsilon) d \epsilon=0
$$

In this case there is a third, strategic, effect of selling futures. This effect also has a deterministic component and a random component. Suppose the firms are risk-neutral. By the strategic effect, a firm that puts units in the forward market positively affects its profit via the spot market strategies of the rival firms. This gives firm $i$ an incentive to sell forward, since by doing so it benefits from rival firms' cuts in their spot sales (Allaz and Vila, 1993). The additional random term has a positive sign and this implies that it works counter to the risk-hedging effect discussed above. This is because, since the rival firms cut their spot sales, the effect of putting one unit forward is less effective at lowering exposure to price shocks.

\footnotetext{
${ }^{20}$ The fall in the forward price originates from the assumption that speculators observe the forward quantities (Ferreira, 2006). Since they anticipate a higher total quantity to be delivered when the spot market closes, they correspondingly lower the prices they bid for the quantities on sale in the futures market.
} 
However, the aggregate random component in equation (21) is still negative and decreasing in $n$. This tells us that firms have an incentive to hedge against risk also in a transparent forward market, but that the marginal gains from doing it become smaller the more firms are around.

Obviously, the importance of the strategic motive depends on the likelihood forward positions are learnt by the players. Moreover, because the risk-hedging and the strategic effects of selling forward on a firm's expected utility are intertwined, it is now clear why it is difficult to disentangle them using data from the field. In the remainder of the paper, our main focus will be on the equilibrium inverse hedge ratio of an individual firm $i$, defined as total-toforward-sales (or $q_{i} / x_{i}$ ) ratio. Though the forward and the spot sales of an individual firm cannot be computed explicitly, we now show how one can easily derive the stochastic process of a firms's inverse hedge ratio. This ratio has useful properties that we will exploit in the empirical application.

After some algebra, the first order condition (19) simplifies to:

$$
\left(a+\sum_{j \neq i} c_{j}-n c_{i}-b x_{i}-b \sum_{j \neq i} x_{j}\right)\left(\frac{1}{n+1}-\frac{2 b \gamma+b(n+1)(1-\gamma)}{2 \rho_{i} \sigma^{2}+b(n+1)^{2}}\right)-x_{i} \frac{2 b \gamma+b(n+1)(1-\gamma)}{2(n+1)}=0
$$

Solving for $x_{i}$ gives:

$$
x_{i}=\frac{2\left(b\left(n^{2}-1\right) \gamma+2 \rho_{i} \sigma^{2}\right)\left(a+\sum_{j \neq i} c_{j}-n c_{i}-b \sum_{j \neq i} x_{j}\right)}{b\left(b(n+1)^{3}-b(n-1)^{2}(n+1) \gamma+2(3+\gamma+n(1-\gamma)) \rho_{i} \sigma^{2}\right)}
$$

Using equation (8), we can write firm $i$ 's total output $q_{i}=s_{i}+x_{i}$ as:

$$
q_{i}=\frac{n}{n+1} x_{i}+\frac{a+\sum_{j \neq i} c_{j}-n c_{i}-b \sum_{j \neq i} x_{j}}{b(n+1)}+\frac{\epsilon}{b(n+1)}
$$

It will prove convenient to measure the relationship between forward and spot sales by the inverse hedge ratio:

$$
\frac{q_{i}}{x_{i}}=\frac{b(n+1)^{2}(n+1+(n-1) \gamma)+2(3+\gamma+(3-\gamma) n) \rho_{i} \sigma^{2}}{2(n+1)\left(b\left(n^{2}-1\right) \gamma+2 \rho_{i} \sigma^{2}\right)}+\frac{1}{b(n+1) x_{i}} \epsilon
$$

As can been seen from equation (24), the inverse hedge ratio is normally distributed. The following proposition discusses some more properties of the equilibrium inverse hedge ratio.

Proposition 1 In equilibrium, the mean of the inverse hedge ratio of a firm $i$, defined as total-to-forward-sales ratio, is given by

$$
\Gamma_{i} \equiv \frac{(n+1)^{2}(n+1+\gamma(n-1))+2(3(n+1)-\gamma(n-1)) \frac{\rho_{i} \sigma^{2}}{b}}{2(n+1)\left(\gamma\left(n^{2}-1\right)+2 \frac{\rho_{i} \sigma^{2}}{b}\right)} .
$$

This mean of the inverse hedge ratio, $\Gamma_{i}$, satisfies the following properties:

(i) It is independent of the demand intercept parameter a and of the firm marginal cost $c_{i}$, 
but increases in the demand slope parameter $b$.

(ii) It decreases as the risk-aversion parameter of the firm $\rho_{i}$ goes up, or as demand volatility $\sigma^{2}$ increases.

(iii) It decreases as the probability that forward positions are observed $\gamma$ increases

(iv) There exists a critical parameter $\tilde{\gamma}$ such that: For all $\gamma \leq(\geq) \tilde{\gamma}, \Gamma_{i}$ increases (decreases) in the number of firms n.

Moreover, if firms are symmetric $\left(c_{i}=c, \rho_{i}=\rho\right.$ for all $\left.i\right)$, the variance of the inverse hedge ratio of the firms decreases in $a, \rho$ and $\sigma^{2}$, and increases in $c, b$ and in $\gamma$.

The proof is in Appendix A.

The main properties of the inverse hedge ratio as stated in Proposition 1 need some further explanation. First, the inverse hedge ratio does not depend on the demand parameter $a$ and the cost parameter $c_{i}$. This means that firms with similar risk aversion hedge in the same way on average, no matter how much they differ in their marginal cost of production. In addition, it is interesting to see that inverse hedge ratios in periods of demand expansion are similar to those in periods of demand contraction. This result, of course, rests on the linearity assumptions of the demand and cost functions. However, it should be seen as a reasonable approximation that is useful because it allows us to estimate the model without cost and demand data.

Inverse hedge ratios go down when firms becomes more risk averse, when demand uncertainty increases, or when the transparency of the forward market goes up. The former two results are driven by the risk-hedging rationale: the higher the degree of risk aversion (or the greater the uncertainty), the more a firm wants to hedge in the forward market instead of selling spot. The latter is explained by the strategic motive, since a high level of contract cover is worth more to a firm the more convincing the commitment is.

The most interesting feature of the inverse hedge ratio, at least for our purposes, is that whether firm entry/exit has an upward or downward effect on this ratio depends on the extent to which the forward market is transparent. If the futures market is relatively opaque and rivals' futures contracts go often unobserved, the strategic effect is hardly present and the contract cover of a firm trades off the the risk-hedging effect against the price effect. In that situation the incentive to hedge against demand shocks becomes weaker (see equation (20)) if more suppliers enter the market, which pushes up the inverse hedge ratio of an individual firm. This is because demand uncertainty is revealed before the spot market opens and therefore the demand shock is partly absorbed by the rivals' spot strategies. As a result, the residual demand of a particular firm at the spot stage is less susceptible to demand shocks the higher the number of competitors. By contrast, the price effect appears not to depend on the number of competitors (see equation (20)). Therefore, it is clear that when the forward market is relatively obscure, inverse hedge ratios increase in the number of suppliers. For the extreme case of $\gamma=0$ we in fact get:

$$
\Gamma_{i}(\gamma=0)=\frac{6 \rho_{i} \sigma^{2}+b(n+1)^{2}}{4 \rho_{i} \sigma^{2}} .
$$


which goes up in $n$.

If the futures market is more transparent and the contract positions of the rivals are regularly observed, in addition to the risk-hedging effect and the price effect, the strategic effect plays a significant role. Note from equation (21) that the strategic effect becomes more prominent as more players are active in the market. This is because for a firm the marginal gains from affecting its rivals' spot market strategies are higher the more competitors it faces. While the risk-hedging and the price effect (weakly) decrease as the number of competitors increases, we show that the strategic effect may have a dominating influence. For the extreme situation $\gamma=1$, we obtain:

$$
\Gamma_{i}(\gamma=1)=1+\frac{1}{n+1}+\frac{2 b}{b\left(n^{2}-1\right)+2 \rho_{i} \sigma^{2}},
$$

which clearly decreases in $n$.

As shown in Proposition 1, for intermediate cases, the relationship between the number of firms and the inverse hedge ratio depends on how likely it is that forward positions will be observed. This is illustrated in Figure 1.

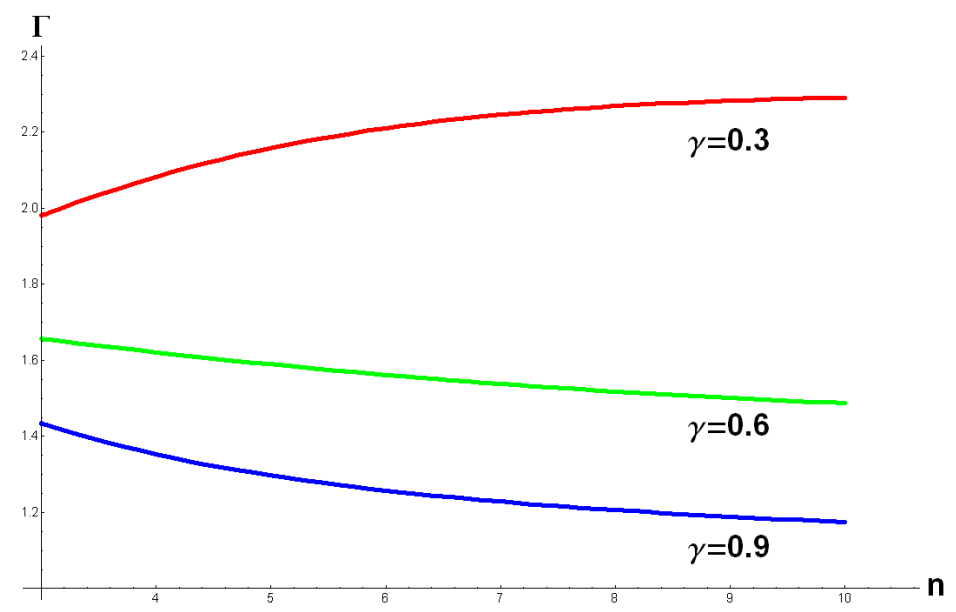

Figure 1: The inverse hedge ratio and the number of firms $\left(\rho_{i}=4, \sigma^{2}=1, b=1\right)$

\section{Empirical application}

We seek to answer the question whether firms sell futures for strategic reasons, for riskhedging considerations, or for both. If firms' forward positions were totally opaque to the agents in the market, strategic reasons would not play any role and therefore the observed inverse hedge ratios in the data would only be explained by risk-hedging considerations. Answering this inquiry thus amounts to finding out the extent to which firms can observe each other's forward sales. Or, in different words, figuring out the ability of the players to forecast correctly the aggregate position of the rivals' upon observing the forward price/index. 
If one were provided with firms' forward and spot sales data corresponding to various levels of observability and risk, one could estimate the effects of these two factors on the hedge ratio. The problem with this approach is that these variables are hard to measure. One could for example gather data from different regional markets. Within-market price dispersion could be used as a measure of price risk. However, it is not clear how to measure the extent to which firms are capable of deducing deviations from changes in the forward price. The analyst would have to make a priori assumptions about the observability parameter $\gamma$. Instead, we propose to estimate the model in Section 2 structurally. We do this for the Dutch wholesale market for natural gas. For this market, we have obtained the minimal set of data: forward and spot sales, churn ratios and number of producers and wholesalers. Before presenting the market under study and the data we have obtained, we discuss the empirical approach. Our results can be found in Section 3.3.

\subsection{Empirical strategy}

The variable of interest is the inverse hedge ratio of an individual firm $i$. As shown above, the inverse hedge ratio of an individual firm $i$ has a random generating process given by:

$$
\frac{q_{i}^{*}}{x_{i}^{*}}=\frac{b(n+1)^{2}(1+n+(n-1) \gamma)+2(3+\gamma+(3-\gamma) n) \rho_{i} \sigma^{2}}{2(n+1)\left(b\left(n^{2}-1\right) \gamma+2 \rho_{i} \sigma^{2}\right)}+\frac{1}{b(n+1) x_{i}^{*}} \epsilon
$$

We can rewrite equation (28) as:

$$
(n+1) q_{i}^{*}=\frac{(n+1)^{2}(1+n+(n-1) \gamma)+2(3+\gamma+(3-\gamma) n) \frac{\rho_{i} \sigma^{2}}{b}}{2\left(\left(n^{2}-1\right) \gamma+2 \frac{\rho_{i} \sigma^{2}}{b}\right)} x_{i}^{*}+\frac{1}{b} \epsilon
$$

Using individual firm level data on total quantities brought to the market, forward sales and number of wholesalers, the system of equations in (29) can be fitted to the data. Identifying assumptions are that the slope of the demand function $b$ and the demand volatility parameter $\sigma$ are constant over the sample period; moreover, we assume that variation in the number of players $n$ is exogenous. ${ }^{21}$ Since these equations are non-linear in the parameters of interest, we will apply non-linear least squares (NLS). Notice that the parameters $\rho_{i}, \sigma$ and $b$ cannot be separately identified. However, with the appropriate (firm-level) data, one could estimate relative risk-aversion parameters across firms, i.e. $\rho_{i} / \rho_{j}$. The identification of these parameters would stem from variation in the hedge ratios of the different firms. If some firms were systematically seen to hedge more than others, this would provide information on the extent to which the former firms have greater risk-aversion than the latter.

The identification of the observability parameter $\gamma$ stems from variation in the number of wholesalers $n$. As shown above, when forward positions are relatively transparent to the

\footnotetext{
${ }^{21}$ It may be argued that the number of players is determined jointly with the hedge ratios. Economic theory suggest the demand and cost parameters as clear determinants of $n$. If this dependence is not clearly controlled for by the variation in the forward sales of a firm $x_{i}$, which clearly depend on $a$ and $c_{i}$, then an endogeneity problem would arise. To deal with this issue, we add a free-entry condition that is estimated jointly with equation (29) (see Section 4.2).
} 
firms, the model predicts that an individual firm responds to entry by decreasing its inverse hedge ratio. By contrast, if firms' forward sales are relatively opaque and rivals' rarely observe them, then an individual firm increases its inverse hedge ratio as a response to entry. It is precisely this differential effect of entry that enables the identification of the observability parameter $\gamma$ using data containing variation in the number of players.

Unfortunately, due to confidentiality reasons, individual firm level data are not publicly available in the market we study and we have only been able to obtain aggregate forward and spot sales. To work with this type of data, we proceed by aggregating at the market level. For this we need to assume that all firms have similar risk aversion parameters, i.e., $\rho_{i}=\rho$ for all $i=1,2, \ldots, n$. Summing up for all firms in (29), we get

$$
\frac{n+1}{n} \sum_{i=1}^{n} q_{i}=\frac{b(n+1)^{2}(1+n+(n-1) \gamma)+2(3+\gamma+(3-\gamma) n) \frac{\rho \sigma^{2}}{b}}{2 n\left(\left(n^{2}-1\right) \gamma+2 \frac{\rho \sigma^{2}}{b}\right)} \sum_{i=1}^{n} x_{i}+\frac{1}{b} \epsilon
$$

Note that $\sum_{i=1}^{n} q_{i}=\sum_{i=1}^{n} s_{i}+\sum_{i=1}^{n} x_{i}$, so that equation (30) can be rewritten as:

$$
\frac{n+1}{n} \sum_{i=1}^{n} s_{i}=\frac{n+1}{n}(\Gamma(\cdot)-1) \sum_{i=1}^{n} x_{i}+\frac{\epsilon}{b}
$$

where $\Gamma(\cdot)$ is the hedge ratio as defined in Proposition 1 for symmetric firms. We fit this equation to the data by applying NLS. The regression results, shown in Section 3.3, tell us whether firms use forward contracts for risk-hedging purposes, for strategic reasons, or for both. We now give some details on the market we study and the data set.

\subsection{The data}

We use data from the Dutch wholesale market for natural gas. For the purpose of this paper, these data are very useful because forward contracts have not been imposed by the regulator so they can be considered endogenous to the market process.

As in many other countries, traditionally, gas supply in the Dutch wholesale market was controlled by a single integrated network company -the $N V$ Nederlandse Gasunie. ${ }^{22}$ Gasunie did not only own the transmission network, but also had control over the national distribution pipelines and the gas supplies. Gas originated from the Dutch gas fields or was imported from foreign producers. ${ }^{23}$ Gasunie sold the gas to industrial customers and distribution companies.

\footnotetext{
${ }^{22}$ Gasunie was a joint venture between De Staatsmijnen (DSM), Shell, Esso and the Dutch State.

${ }^{23}$ The sources of supply are similar in recent days. In 2008 there were 35 production fields and 17 import entry points (GTS, 2008). The bulk of Dutch gas production takes place in the Groningen gas field. After the discovery of this field in 1959, the Nederlandse Aardolie Maatschappij (NAM), a joint venture between Shell and Esso, obtained a governmental concession to explore and exploit this gas field. The NAM was however obliged to sell all the gas extracted from the Groningen field (and other small fields in the Netherlands) to Gasunie.
} 
Market deregulation in the Netherlands started back in the late 1990s with the Price Transparency Directive, but gained full momentum with the First Gas Directive of the European Union in 1998. This ruling abolished import monopolies, forced the opening of markets and imposed the accounting unbundling of vertically integrated network companies. The Second Gas Directive of the European Union in 2003 furthered the liberalisation process by requiring full market opening, regulated third party network access, regulated or negotiated access to storage and legal unbundling of integrated network companies. As a consequence of this directive, Gasunie was split up into two independent companies: Gas Transportation Services (GTS), which controls the national transmission network, and Gasterra, which is engaged in gas wholesaling. The second directive also required the creation of national energy regulators.

To attain a well-functioning wholesale gas market in The Netherlands, the Title Transfer Facility (TTF) was created in 2003. The TTF is a virtual trading hub that offers market parties/shippers the possibility to buy and sell gas that is already injected into the national gas transmission grid, or for which transportation capacity has already been booked. Thanks to the TTF gas can easily change hands before it is extracted at a specific local or export exit point. This triggered the entry of new players into the Dutch market. ${ }^{24}$ The TTF made the emergence of gas exchanges possible. APX Gas NL B.V. runs an exchange for spot contracts. At APX, market parties can trade standardized contracts for gas delivery one day ahead and within the same day. ENDEX N.V. runs an exchange for a variety of gas futures contracts. $^{25}$ At the end of 2008 ENDEX N.V. was taken over by APX B.V., which is also the owner of APX Gas NL B.V.

The TTF allows gas buyers in the wholesale market to hold a portfolio of different types of gas products. Long-term take-or-pay contracts used to be the dominant contract type in the industry. Nowadays a buyer can buy gas on a short term basis at the trading hub. Since gas demand typically has a seasonal pattern, firms gain in flexibility by participating in this new market. Over the years we have witnessed an increase in volumes traded at the TTF. By 2008, a substantial share of 20 percent of gas that flows through the GTS transport system reached the trading hub. The Dutch regulator expects that in the future the TTF will be sufficiently liquid so as to offer market participants all the hedging opportunities they need. ${ }^{26}$ Our data set consists of a substantial fraction (approximately 75 percent) of all forward and spot contracts traded at the Dutch TTF for the period from April 2003 until June 2008.

\footnotetext{
${ }^{24}$ New players include new wholesale companies such as Gaz de France, BP, EON, Gazprom, RWE, Statoil, Total, etc., as well as new financial players such as JP Morgan, The Royal Bank of Scotland, BNP Paribas, Morgan Stanley, Citygroup, Barclays Bank, etc. By contrast, there has not been much entry of new retailers in the TTF. What has happened is that the existing distribution companies (Essent, Nuon, Eneco, GDF Suez, etc.) have become active outside their traditional territories as well as abroad.

${ }^{25}$ The minimum length of a contract is one month and the maximum length is one (calendar) year. Contracts can range from a month ahead to three years ahead of delivery. In Appendix D we provide more details on the types of contracts traded at the TTF.

${ }^{26}$ Most of the TTF-traded gas is high-calorific, which is gas that is mostly used for industrial and exporting purposes. High-calorific can also be converted into low-calorific gas, which is the gas intended for domestic residential usage.
} 
These data were provided by the company ICIS Heren. ${ }^{27}$ In addition, we obtained data from the transport operator GTS on the number of wholesalers active every month, on the daily churn rates and on the total daily volumes. ${ }^{28}$ Unfortunately, we do not have information on the identity of the trading partners so we are unable to perform the analysis at the firm level. As explained earlier, if firms do not differ much in their aversion to risk, they will hedge in a similar fashion, even if there exist significant cost differences across them.

Transactions can be either facilitated by brokers, or exchange-based, or the outcome of bilateral negotiations. All these three types of transactions are included in our data set, but we cannot distinguish between them in the sense that we cannot tell whether a transaction is over-the-counter or has occurred at the centralized exchange ENDEX. As said before, there are several types of contracts traded at TTF. For a given trading day, we are interested, on the one hand, in the total volume of gas delivered and, on the other hand, in the amount that has been sold forward. To compute all the gas delivered in a given date, we sum all the quantities specified in different contracts that call for delivery on such a day. To compute how much of this volume is contracted forward, we need to make an assumption about the nature of uncertainty in this market. We make the assumption that only day-ahead and within-day contracts form the spot market so the rest of the contracts are considered futures contracts. $^{29}$

To be clear, suppose that in year 2003, three products have been traded: (i) a forward contract traded on November 3 that calls for delivery of 720 MegaWatt hour (MWh) each day in December 2003, (ii) a day-ahead contract traded on December 6, 2003 for delivery of 4,320 MWh the next day, and (iii) a spot contract traded on December 20, 2003 for delivery of 1,440 MWh the same day. Then, except for two days, December 7 and 20, for each day in December 2003 the delivery volume is 720 MWh. On December 7, the total delivery volume equals $(720+4,320=) 5,040 \mathrm{MWh}$ while on December 20, the delivery volume is $(720+1,440=) 2,160 \mathrm{MWh}$. As a result, the hedge ratio is 1 for all days of December 2003 except for December 7, with an inverse hedge ratio of 8 , and December 20, with an inverse hedge ratio of 3 .

One difficulty of the data at hand is that a substantial part of the transactions we observe concerns contracts that are traded with or between speculators. Since financial traders

\footnotetext{
${ }^{27}$ ICIS Heren (http://www.icis.com/heren/) is a leading specialized information provider for energy markets. The company publishes price assessments, indices, news and analysis for various energy markets. ICIS Heren gathers daily price and quantity information from brokers and directly from the participants in the industry via telephone calls.

${ }^{28}$ The participants in the industry must make nominations to the transport operator once the gas changes hands. In this way, the transport operator receives the necessary information to compute total traded volumes and the churn rates. Using the data on total volumes delivered at the TTF, we estimate that our data contains well above 50 percent of the total market.

${ }^{29}$ We have discussed the validity of this assumption with participants in this industry. At the margin, the main driver of demand is temperature. Therefore, if any, the main source of uncertainty here is due to temperature fluctuations. According to the participants, the weather predictions one day ahead are quite accurate. Moreover, within-day and day-ahead deals are conducted at one and the same exchange (APX) while contracts with longer duration are traded on a different exchange (ENDEX). This suggests that the industry considers day-ahead and within-day contracts as being of similar type.
} 
must have zero net positions before delivery, many of the contracts we see are re-trades and do not involve volumes that are finally brought to the market. Fortunately, we can deal with this issue using data on churn rates (net-to-gross-volume ratios). Churn rates are reported by GTS. These rates do not distinguish between forward trades and spot market trades. Obviously, actual churn rates for spot market transactions are much lower than those corresponding to forward trades, since the length of time to resell contracts is rather short in the spot market. In what follows, we assume forward transactions have a churn rate equal to the churn rate reported by the GTS; for spot market trades, we assume the churn rate equals one. ${ }^{30}$ Table 1 provides some descriptive statistics of our data and Figure 2 displays the forward sales adjusted for the churn rate, as well as the spot market sales. ${ }^{31}$

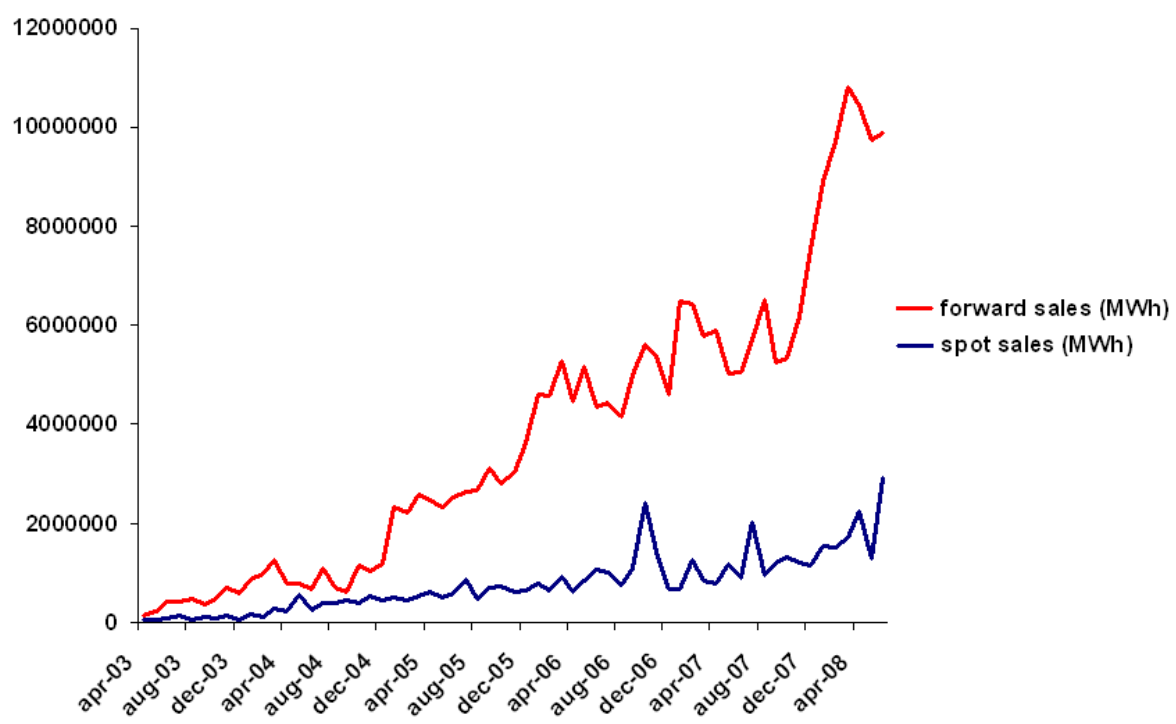

Figure 2: Forward market and spot market sales

The descriptive statistics reveal four interesting aspects of the data. First, volumes traded at the TTF have gone up a great deal. ${ }^{32}$ In fact, by 2008 the TTF became the second largest

\footnotetext{
${ }^{30}$ In different words, we are assuming speculators do not take positions during the time the spot market is open. If we had information on the identity of the traders, we could check the validity of this assumption.

${ }^{31}$ Besides data on traded volumes, Table 1 also contains information on forward prices and spot prices. The forward price indices we report concern monthly contracts. We compute four different forward price indices: the price index obtained using all transactions that take place (1) more than one month before the month of delivery; (2) in the first half of the month preceding delivery; (3) in the last half of the month before delivery (4) in the last two days before delivery. In Table 1, we only report the index for monthly contracts traded in the first half of the month preceding the delivery month. The other indices show a very similar pattern. Spot prices are determined by computing an index for all the day-ahead deals included in our data set.

${ }^{32}$ Currently net volumes in the TTF are approximately equal to the total supplies of natural gas to large industrial users in The Netherlands, including the electricity generating companies. This is about $10 \%$ of the total amount of gas that enters the Dutch pipeline system (about $43 \%$ of the gas that enters the Netherlands is 'transit' gas, i.e., exports to other countries).
} 


\begin{tabular}{|c|c|c|c|c|c|}
\hline Year & Variable & Min & Max & Mean & Std. Dev. \\
\hline \multirow[t]{9}{*}{2003} & Wholesalers & 9 & 11 & 10.11 & 0.93 \\
\hline & Wholesalers $80 \%$ & 4 & 6 & 5.22 & 0.67 \\
\hline & Spot (GWh) & 63.96 & 145.54 & 93.25 & 34.05 \\
\hline & Forward (GWh) & 193.92 & 1646.64 & 856.91 & 491.32 \\
\hline & Churn rate & 1.42 & 2.67 & 1.92 & 0.41 \\
\hline & Net forward (GWh) & 136.71 & 712.28 & 419.61 & 172.42 \\
\hline & Inv. hedge ratio & 1.11 & 1.49 & 1.26 & 0.12 \\
\hline & Forward price & 10.10 & 15.09 & 11.56 & 1.88 \\
\hline & Spot price & 8.42 & 14.26 & 11.08 & 2.03 \\
\hline \multirow[t]{9}{*}{2004} & Wholesalers & 11 & 15 & 13 & 1.48 \\
\hline & Wholesalers $80 \%$ & 5 & 8 & 6.5 & 0.90 \\
\hline & Spot (GWh) & 133.44 & 561.84 & 353.82 & 137.08 \\
\hline & Forward (GWh) & 1512 & 3494.02 & 2455.11 & 638.83 \\
\hline & Churn rate & 2.04 & 3.15 & 2.65 & 0.37 \\
\hline & Net forward (GWh) & 624.38 & 1281.44 & 932.05 & 220.23 \\
\hline & Inv. hedge ratio & 1.14 & 1.73 & 1.4 & 0.19 \\
\hline & Forward price & 10.34 & 14.78 & 12.06 & 1.60 \\
\hline & Spot price & 10.67 & 14.88 & 11.84 & 1.30 \\
\hline \multirow[t]{9}{*}{2005} & Wholesalers & 14 & 20 & 17.17 & 1.90 \\
\hline & Wholesalers $80 \%$ & 7 & 10 & 8.58 & 0.9 \\
\hline & Spot (GWh) & 433.92 & 866.88 & 599.64 & 126.26 \\
\hline & Forward (GWh) & 6479.28 & 10911.60 & 8322.37 & 1183.82 \\
\hline & Churn rate & 2.69 & 3.34 & 3.09 & 0.18 \\
\hline & Net forward (GWh) & 2220.24 & 3622.44 & 2699.18 & 397.34 \\
\hline & Inv. hedge ratio & 1.18 & 1.33 & 1.22 & 0.04 \\
\hline & Forward price & 13.48 & 22.09 & 16.32 & 2.61 \\
\hline & Spot price & 14.20 & 23.91 & 16.66 & 2.99 \\
\hline \multirow[t]{9}{*}{2006} & Wholesalers & 21 & 24 & 22.42 & 1.24 \\
\hline & Wholesalers $80 \%$ & 10 & 11 & 10.25 & 0.45 \\
\hline & Spot (GWh) & 621.60 & 2397.68 & 1022.42 & 487.18 \\
\hline & Forward (GWh) & 13030.15 & 19472.21 & 15788.77 & 2150.13 \\
\hline & Churn rate & 2.83 & 4.23 & 3.29 & 0.41 \\
\hline & Net forward (GWh) & 4166.79 & 5615.75 & 4805.13 & 471.61 \\
\hline & Inv. hedge ratio & 1.14 & 1.43 & 1.21 & 0.08 \\
\hline & Forward price & 19.35 & 27.35 & 22.65 & 2.92 \\
\hline & Spot price & 14.18 & 28.07 & 20.82 & 3.95 \\
\hline \multirow[t]{9}{*}{2007} & Wholesalers & 25 & 28 & 25.67 & 0.98 \\
\hline & Wholesalers $80 \%$ & 11 & 14 & 12.75 & 1.06 \\
\hline & Spot (GWh) & 684.34 & 2027.78 & 1130.29 & 353.96 \\
\hline & Forward (GWh) & 18279.17 & 26240.35 & 22141.36 & 2734.63 \\
\hline & Churn rate & 2.84 & 4.66 & 3.77 & 0.56 \\
\hline & Net forward (GWh) & 5033.53 & 7520.37 & 5934.65 & 732.21 \\
\hline & Inv. hedge ratio & 1.11 & 1.35 & 1.19 & 0.07 \\
\hline & Forward price & 10.03 & 25.56 & 14.99 & 5.28 \\
\hline & Spot price & 9.16 & 22.87 & 14.71 & 4.93 \\
\hline \multirow[t]{9}{*}{2008} & Wholesalers & 28 & 29 & 28.67 & 0.52 \\
\hline & Wholesalers $80 \%$ & 12 & 12 & 12 & 0 \\
\hline & Spot (GWh) & 1310.18 & 2910.58 & 1875.08 & 603.48 \\
\hline & Forward (GWh) & 28625.40 & 35767.02 & 33389.21 & 2531.02 \\
\hline & Churn rate & 3.22 & 3.57 & 3.37 & 0.12 \\
\hline & Net forward (GWh) & 8900.29 & 10797.62 & 9911.70 & 659.24 \\
\hline & Inv. hedge ratio & 1.13 & 1.29 & 1.19 & 0.06 \\
\hline & Forward price & 21.79 & 25.94 & 24.26 & 1.57 \\
\hline & Spot price & 22.73 & 26.64 & 24.70 & 1.44 \\
\hline
\end{tabular}

Notes: Year 2003 averaged over 9 months. Year 2008 over 6 months.

Table 1: Descriptive Statistics (monthly averages) 
gas trading hub in Europe, both in terms of traded volume and net (physical) flow. ${ }^{33}$ A first explanation for this phenomenon is that, as compared to for example the Zeebrugge hub in Belgium, the TTF benefits from the absence of third-party access exemptions to the Dutch pipeline system. A second issue is that the entry/exit points to the Dutch pipeline system are well interconnected and this allows for the TTF to function as a virtual hub, which relaxes the physical constraints imposed by the capacities of the various pipelines. Finally, adding to the attractiveness of the Dutch trading hub as compared to signing long-term contracts is the opening of the BBL pipeline in 2006, which connects the Netherlands and the UK. The BBL pipeline allows TTF-traded gas to be shipped to the UK and this brings TTF prices down and more in line with UK prices.

A second aspect of the data is that a significant part of the total volume traded at the TTF is hedged (between 60 and $90 \%$ ). It is also remarkable that the hedge ratio has increased over time but, by no means, it has changed by the order of magnitude the volumes have changed. Furthermore, we note that the standard deviation of the inverse hedge ratio seems to have gone down over the sample period. The latter two observations appear to be in line with our model of firm behavior (inverse hedge ratios are mean independent of the strength of the demand parameter and have a standard deviation negatively correlated with it, see Proposition 1). Finally, it can be seen from Table 1 that forward prices and spot prices are closely linked, though the former are in general somewhat higher than the latter. ${ }^{34}$

As discussed earlier, identification of the key parameters of the model requires variation in the number of wholesalers operating in the market. The TTF is a market where in fact there has been a steady increase in the number of participants. However, from our data on transactions we cannot extract the number of wholesalers since we do not have information on the identity of the traders engaged in a transaction. We obtained data on the number of active wholesalers in a given month from the GTS. ${ }^{35}$ Since some wholesalers are probably very small and have no market power whatsoever, we also asked for the number of active wholesalers making up for 60 and 80 percent of total delivery. Figure 3 shows the evolution of the total number of active wholesalers, as well as the development of the number of suppliers that account for more than 60 and 80 percent of the gas delivered in the TTF. Note that not only more gas wholesalers have entered the TTF in the period under analysis, but also that, as time has elapsed, the 60 and 80 percent market share has become distributed over more firms. This suggests that the supply of gas has become less concentrated in the Netherlands.

\footnotetext{
${ }^{33}$ The National Balancing Point (NBP) in the UK, introduced in 1996, has long since been the most liquid hub in Europe.

${ }^{34}$ Using the four different forward price indices, we perform an ANOVA test of the null hypothesis that spot and forward prices are statistically similar to each other. For three out of the four forward price indices, the hypothesis cannot be rejected (the only index that appears to be significantly different than the spot price index is the one computed from transactions that take place longer than a month before delivery).

${ }^{35}$ To conduct transactions at the TTF, participants must first subscribe with the TTF either as wholesalers, industrial customers, retailers or pure traders. The subscription can be made for a single gas month or for a full calendar year. Subscribing involves the payment of some fixed fees and, in addition, traders have to pay some variable fees for the volumes traded.
} 


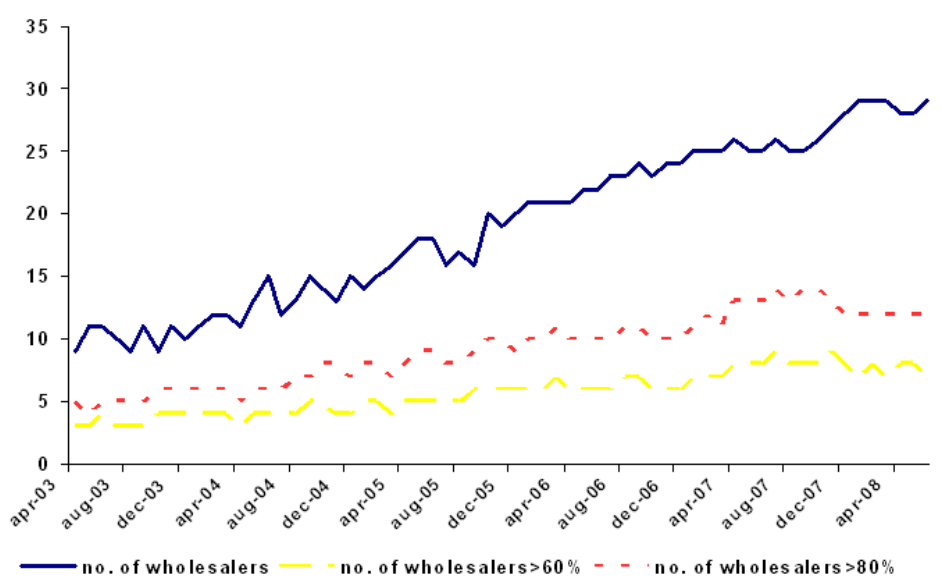

Figure 3: Number of wholesalers active at TTF

Given the monthly nature of our data on the number of active wholesalers, we compute aggregate monthly delivery forward and spot volumes and conduct the analysis using 63 monthly observations. To get a first impression of whether gas wholesalers trade forward contracts for strategic reasons, we pool together the months in which the number of active suppliers that serve $80 \%$ of the market is the same and compute the average hedge ratio for those months. We then regress the hedge ratio on a constant and on the number of wholesalers. Figure 4 displays the relation between the number of wholesalers trading at the $\mathrm{TTF}$ and the average ratio of interest. The dots in the figure represent the average ratio for a given number of wholesale firms in our data set, while the dashed line shows the estimated relation between the number of wholesalers and the inverse hedge ratio. The results of the regression indicate that this relation is negative, which, according to the theoretical model, suggests that forward contracts are used as strategic instruments. ${ }^{36}$ Since this regression does not allow us to learn the extent to which the players' positions are observed, we proceed by estimating the model structurally.

\subsection{Results}

The relation to be estimated can be written as (see equation (31)):

$$
\frac{n_{t}+1}{n_{t}} \sum_{i=1}^{n} s_{i t}=\frac{n_{t}+1}{n_{t}}\left(\Gamma\left(n_{t}, \gamma, \lambda\right)-1\right) \sum_{i=1}^{n} x_{i t}+\frac{\epsilon_{t}}{b}, \quad \epsilon_{t} \sim N\left(0, \sigma^{2}\right)
$$

where $t$ indexes the time period (month) and $\gamma$ and $\lambda \equiv \frac{\rho \sigma^{2}}{b}$ are the parameters of interest. The NLS regression results are summarized in Table 2.

\footnotetext{
${ }^{36}$ More precisely, we estimate by OLS the model $\hat{\Gamma}_{n}=\alpha+\beta n+u_{n}$, where $\hat{\Gamma}_{n}$ is the average inverse hedge ratio for a given number of wholesale firms, $n$ the number of wholesalers and $u_{n}$ the usual error term. The estimates become $\hat{\alpha}=1.36$ and $\hat{\beta}=-0.01$, with t-statistics being equal to 21.97 and -1.66 , respectively.
} 


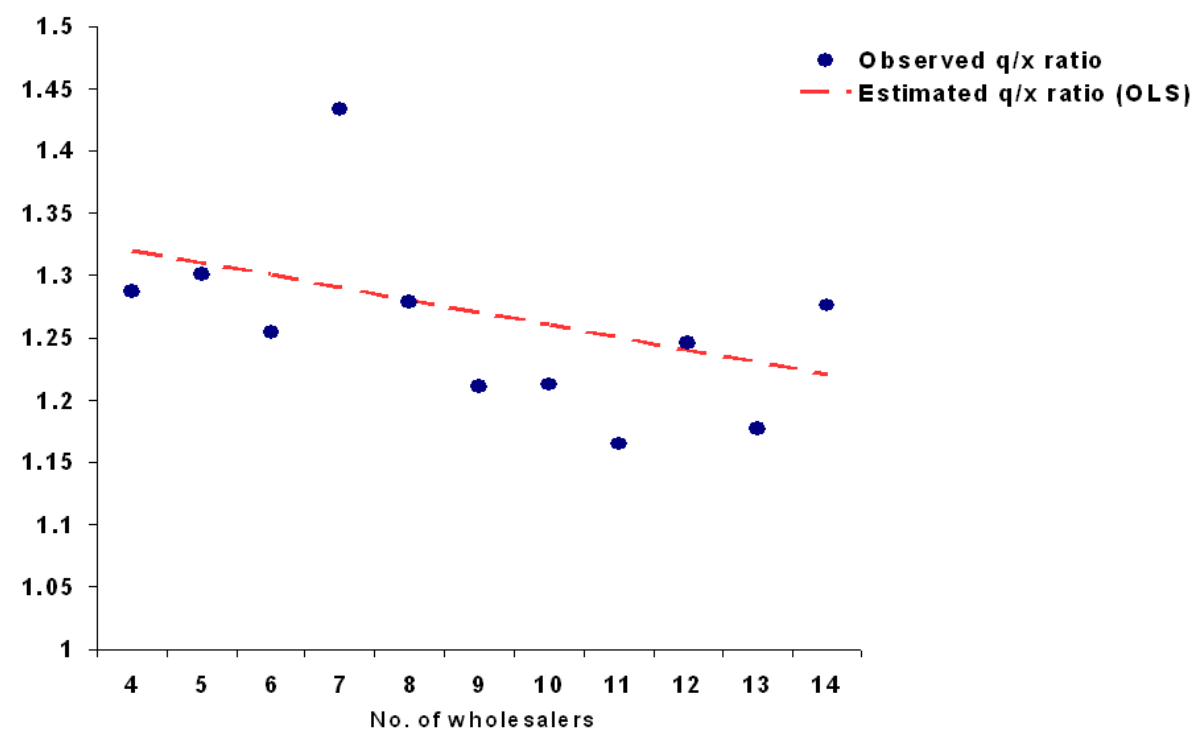

Figure 4: Inverse hedge ratio and the number of wholesalers

\begin{tabular}{ccc}
\hline \hline Parameter & Estimate & t-statistic \\
\hline$\lambda$ & 11.98 & 0.45 \\
$\gamma$ & $0.83^{*}$ & 25.96 \\
\hline$R^{2}=0.70$ & \\
\hline \hline
\end{tabular}

Table 2: NLS regression results

As can be seen from Table 2, the estimate for the observability parameter, $\hat{\gamma}$, is equal to 0.83 and is highly significant. We view this result as a first piece of evidence that strategic considerations play an important role in explaining the hedge ratios observed in the data. As said above, this can be interpreted as if firms attached approximately 80 percent probability to the event that their forward positions are correctly forecasted by the rival firms upon observing the forward price. Seen from the perspective that most transactions at the TTF occur OTC, we find the result that the forward market is quite transparent interesting. It actually means that the market by itself is able to activate the role of forward sales as a commitment device.

The estimate for the risk aversion parameter, $\hat{\lambda}$, turns out not to be significant. This suggests that there is not clear evidence that risk-hedging is a key factor explaining observed hedge ratios in the Dutch natural gas market. ${ }^{37}$

The previous regression assumes demand volatility is constant over the sample period. If

\footnotetext{
${ }^{37}$ We have also estimated equation (32) for the case where $n$ equals the number of all active wholesalers. We obtain similar results. The estimate for $\gamma$ is equal to 0.76 and is significant at the 1 percent level, while $\lambda$, in this case becoming nearly zero, is again non-significant.
} 
demand has become more (or less) volatile as time has elapsed, not controlling properly for such variation may lead to some form of omitted variable bias. Of course, changes in $\sigma^{2}$ are controlled for by changes in the forward sales. However, since $\sigma^{2}$ affects the expression (32) directly, this control may be insufficient.

To explore this issue, we first construct a measure of demand volatility using spot market prices and use it to increase the variation in the data. Using equation (24), and rearranging, we can write the equilibrium spot price as follows:

$$
p_{t}=a_{t}-b \sum_{i} \Gamma_{i t} x_{i t}+\frac{1}{\left(n_{t}+1\right)} \epsilon_{t}
$$

From this expression we can compute a measure of demand volatility:

$$
\sigma_{t}^{2}=\left(n_{t}+1\right)^{2} \sigma_{p_{t}}^{2}
$$

To determine the monthly volatility of demand shocks, we thus need some measure for price variability. For this, we first proxy daily spot prices by computing a weighted price index for day-ahead contracts. Then, monthly demand volatility, $\sigma_{t}^{2}$, is obtained by calculating the variance of the spot prices within a given month and multiplying this measure by $\left(n_{t}+1\right)^{2} .^{38}$

Figure 5 plots (the natural logarithm of) our estimate for the monthly demand volatility. The graph shows that demand has become more volatile over the sample period. This should explain part of the observed decrease in the inverse hedge ratios and, as a result, we would expect to obtain a lower estimate of the transparency parameter $\gamma$. The new estimates of equation (32) are in Table 3. In fact, the new estimate of the transparency parameter $\gamma$ is somewhat lower and continues to be highly significant. Again we do not obtain significant evidence that risk is an important issue in this market.

\begin{tabular}{ccc}
\hline \hline Parameter & Estimate & t-statistic \\
\hline$\rho / b$ & 9189.1 & 0.00 \\
$\gamma$ & $0.70^{*}$ & 30.83 \\
\hline$R^{2}=0.70$ & \\
\hline \hline & \\
\hline
\end{tabular}

Table 3: NLS regression with demand volatility measure

It is conceivable that forward market transparency has increased over time. First, one can imagine that market participants' ability to interpret price signals has improved as time has elapsed. Second, it is also reasonable to believe that the quality and the quantity of the price

\footnotetext{
${ }^{38}$ Notice that using ex-post price variation as a proxy for demand uncertainty relies on the assumption that firms have ex-ante perfect foresight about future (spot) prices. Campa and Goldberg (1993) use this approach to study the effect of exchange rate volatility on entry of foreign firms in the US market during the 1980 s.
} 


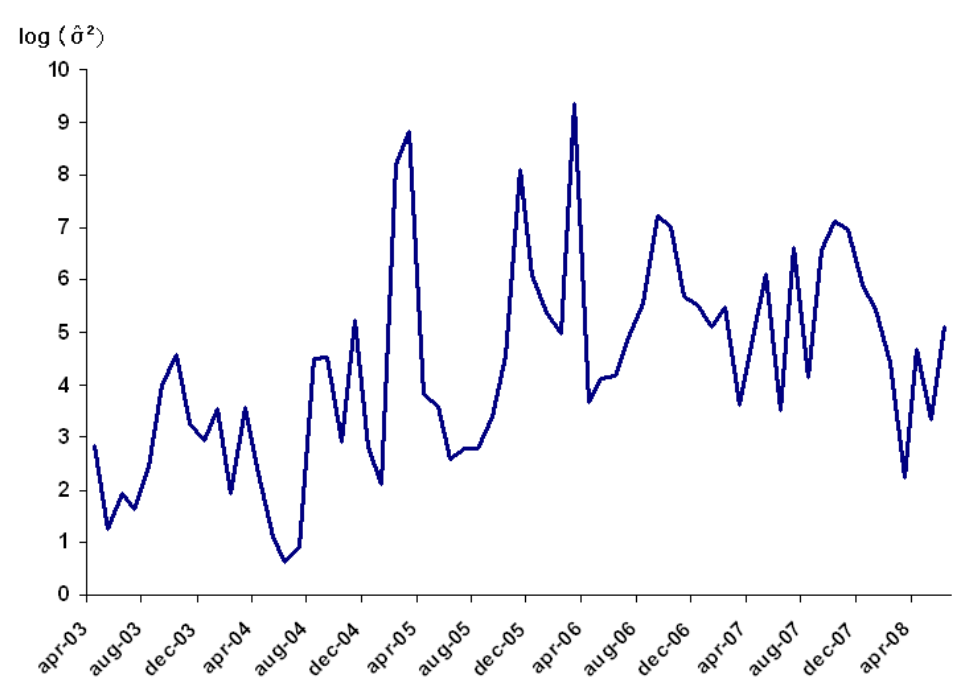

Figure 5: measure of demand uncertainty

indices available in the market has increased over time. Price information is now provided by information agencies such as ICIS Heren and Argus Media Ltd., ${ }^{39}$ brokers' associations such as LEBA ${ }^{40}$ as well as the centralized marketplace ENDEX. Finally, the share of trades conducted (or cleared) at the gas exchange (vis-à-vis OTC) has increased over time and, since the exchange may be considered a more transparent marketplace than the OTC market, this adds to the supposition that the forward market as a whole has become more transparent. If this conjecture is borne by the data, we should observe an increase in the observability parameter $\gamma$ over time.

To test this learning hypothesis, we introduce year dummies into the empirical model in (32). We continue to use the proxy for changes in demand volatility. The new estimates are given in Table 4. The results suggest that wholesalers' ability to infer deviations from equilibrium play has indeed increased over time.

We have searched for explanations for the result that there is no evidence that risk-hedging is an important factor to explain the observed inverse hedge ratios. One possible explanation is that being the strategic effect present and relatively strong, the incentives to hedge become rather weak. In fact, when $\gamma$ is close to one, and for the firm numbers in our data (from 4 to 14 players), the share of the hedged quantity in total sales is already relatively large so the residual demand of a firm is quite low. This makes it rather difficult to precisely estimate the risk aversion parameter. To substantiate this observation, we plot the fit of the estimated model (with and without a proxy for $\sigma^{2}$ ), along with those which would prevail if the wholesalers were risk-neutral $(\lambda=0.01)$ or very risk averse $(\lambda=100,000) .{ }^{41}$ The graph illustrates that the inverse hedge ratios predicted by the different levels of risk aversion are

\footnotetext{
${ }^{39}$ www.argusmedia.com

${ }^{40}$ London Energy Brokers' Association (www.leba.org.uk)

${ }^{41}$ To plot the fit of the regression with a proxy for demand volatility included, we take the sample mean of $\sigma^{2}$ and multiply this measure by the estimated $\rho / b$ to get an estimate for $\lambda$.
} 


\begin{tabular}{ccc}
\hline \hline Parameter & Estimate & t-statistic \\
\hline$\rho / b$ & 9967.8 & 0.00 \\
$\gamma_{2003}$ & 0.81 & 1.19 \\
$\gamma_{2004}$ & 0.30 & 0.99 \\
$\gamma_{2005}$ & $0.67^{*}$ & 7.42 \\
$\gamma_{2006}$ & $0.66^{*}$ & 13.20 \\
$\gamma_{2007}$ & $0.71^{*}$ & 18.12 \\
$\gamma_{2008}$ & $0.71^{*}$ & 20.76 \\
\hline$R^{2}=0.72$ & \\
\hline \hline Notes: $n$ equal to wholesalers 80\% of market \\
* Significant at the 1 percent level
\end{tabular}

Table 4: NLS regression with demand volatility measure and year dummies.

somewhat similar; as a result, one would need a very rich data set to precisely estimate the risk aversion parameter.

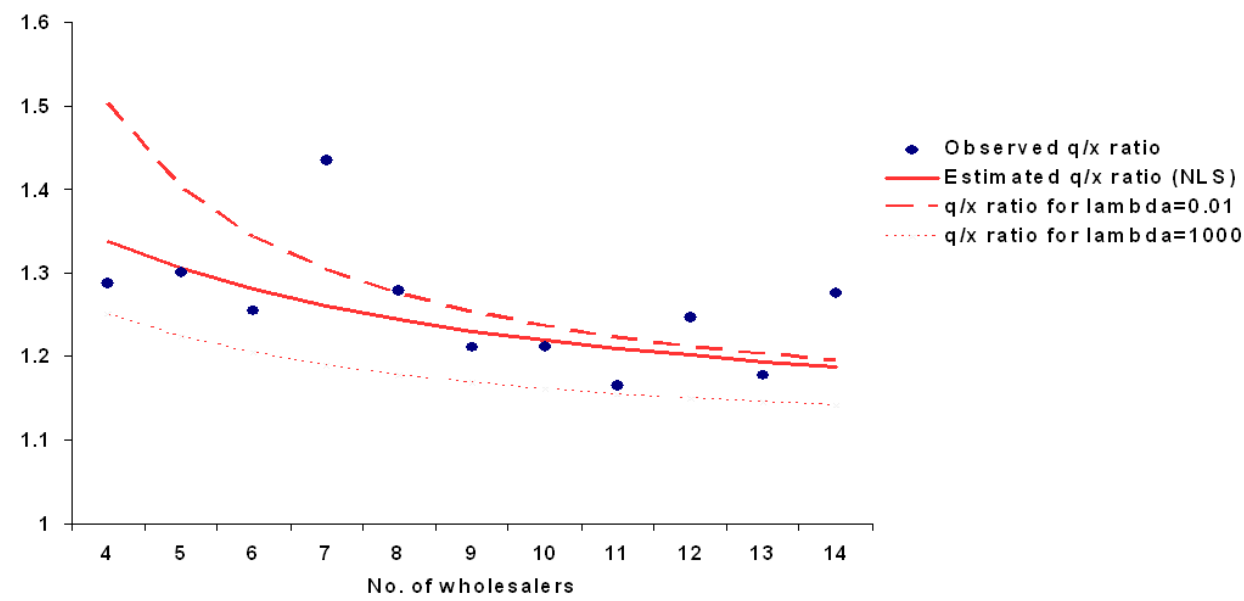

Figure 6: Fit of the model

Finally, we note that most TTF-trade is on high-calorific gas, for which demand is mainly industrial and for exporting purposes and therefore less subject to unpredictable weather shocks (see NMa/DTe, 2007). The other type of gas sold at the TTF is low-calorific gas. Demand for this type of gas is weather-driven to a larger extent because this type of gas is meant for household usage; however, due to limited conversion capacity, most of the lowcalorific gas delivered in the Netherlands does not pass the TTF. 


\section{Discussion and further results}

\subsection{Uncertain spot market}

In the model studied above, we have assumed that firms operate in the spot market in the absence of uncertainty. Therefore, we have modeled a market where firms observe the demand shocks before they decide how much gas to put in the spot market. Arguably, the demand may still remain uncertain at that moment. In such a case, firms cannot condition their spot strategies on the demand realizations. To see whether our results depend on this assumption, we now develop a model in which firms do not observe price shocks before the spot market opens. Of course, as before, the difference between the forward and the spot market is that at the forward stage the firms can lock-in a price for their forward quantities, while the price received for their spot quantities is random.

In this new setting, a firm $i$ that chooses its spot market strategy $s_{i}$ aims at maximizing the expected utility from its spot market profits:

$$
E\left[u\left(\pi_{i}^{s}\right]=\int-e^{-\rho\left(p-c_{i}\right) s_{i}} f(\epsilon) d \epsilon\right.
$$

To simplify the derivations, let us focus right away on the symmetric case where all firms are equally risk averse and have similar marginal costs of production. Given a forward strategy profile, when $I=1$ the equilibrium spot market output of a firm $i$ solves the first order condition: ${ }^{42}$

$$
s_{i}^{I=1}=\frac{a-c-b x_{i}-b(n-1) x_{-i}}{b(n+1)+\rho \sigma^{2}}
$$

where $x_{i}$ denotes firm $i$ 's forward sales and $x_{-i}$ refers to the forward sales of firms other than $i$. In this case, the conditional reduced-form equilibrium profit is

$$
\pi_{i}^{I=1}=\left(\left(b+\rho \sigma^{2}\right) s_{i}^{I=1}+\epsilon\right) s_{i}^{I=1}+(f-c) x_{i}
$$

where $f$, as above, denotes the forward price.

When forward positions of the rival firms are not observable, $I=0$, the equilibrium spot market output of firm $i$ is given by

$$
s_{i}^{I=0}=\frac{\left(2 b+\rho \sigma^{2}\right)\left(a-c-b(n-1) \hat{x}_{-i}\right)+b^{2}(n-1) \hat{x}_{i}-b\left(b(n+1)+\rho \sigma^{2}\right) x_{i}}{\left(2 b+\rho \sigma^{2}\right)\left(b(n+1)+\rho \sigma^{2}\right)}
$$

where $\hat{x}_{i}$ denotes rival firms' conjecture about the position of firm $i$, and $\hat{x}_{-i}$ refers to the conjectures about the forward positions of firms other than $i$. The equilibrium payoff in this case of no observability equals

$$
\pi_{i}^{I=0}=\left(\left(b+\rho \sigma^{2}\right) s_{i}^{I=0}+\epsilon\right) s_{i}^{I=0}+(f-c) x_{i}
$$

\footnotetext{
${ }^{42}$ Details of the derivations are available from the authors upon request.
} 
At the forward market stage, a firm $i$ picks its amount of forward sales $x_{i}$ to maximize its expected utility. The equivalent to the FOC in equation (19) is given by:

$\int \rho e^{-\rho \pi}\left(-b x+\rho \sigma^{2} s+(1-\gamma) \frac{b\left(b x-\rho \sigma^{2} s-\epsilon\right)}{2 b+\rho \sigma^{2}}-\gamma \frac{b\left(\rho \sigma^{2} s-b x-(n-1) b(s+x)+\epsilon\right)}{b(n+1)+\rho \sigma^{2}}\right) f(\epsilon) d \epsilon=0$

where we have already imposed the symmetry of equilibrium strategies and the correctness of equilibrium conjectures conditions, i.e. $x_{i}=x_{i-}=\hat{x}_{-i}=\hat{x}_{-i}$. Solving for the equilibrium forward sales we obtain:

$$
x=\frac{(a-c)\left(2+\frac{\rho \sigma^{2}}{b}\right)\left(\gamma(n-1)+(n+1) \frac{\rho \sigma^{2}}{b}+\frac{\rho^{2} \sigma^{4}}{b^{2}}\right)}{b\left(\gamma(n-1)^{2}+(n+1)^{2}+\left(3(n+1)^{2}-2 \gamma(n-1)\right) \frac{\rho \sigma^{2}}{b}+(n(n+5)-\gamma(n-1)+3) \frac{\rho^{2} \sigma^{4}}{b^{2}}+(n+1) \frac{\rho^{3} \sigma^{6}}{b^{3}}\right)}
$$

Building on this expression, we can state the following result:

Proposition 2 Suppose that firms do not observe the demand shocks before the spot market opens. Then the inverse hedge ratio of a firm $i$ is deterministic and given by

$$
\hat{\Gamma} \equiv \frac{\gamma(n-1)+\left(n+1+\frac{\rho \sigma^{2}}{b}\right)\left(1+3 \frac{\rho \sigma^{2}}{b}+\left(\frac{\rho \sigma^{2}}{b}\right)^{2}\right)}{\left(2+\frac{\rho \sigma^{2}}{b}\right)\left(\gamma(n-1)+\frac{\rho \sigma^{2}}{b}\left(n+1+\frac{\rho \sigma^{2}}{b}\right)\right)}
$$

The inverse hedge ratio $\hat{\Gamma}$ is independent of the demand intercept parameter a and of the firm marginal cost $c$, increases in the demand slope parameter $b$, decreases in $\rho$ and in $\sigma^{2}$, decreases in $\gamma$ and is (weakly) monotonically decreasing in the number of firms $n$.

Compared to the inverse hedge ratios in Proposition 1, we see that when spot market strategies cannot be adapted to accommodate the demand shocks, inverse hedge ratios are always (weakly) decreasing in the number of players. The intuition behind this result is as follows. As before, the incentives of a firm to sell forward are governed by a price effect, a risk-hedging effect and a strategic effect. The price effect is again constant in the number of firms. Since firms cannot adapt their spot strategies to demand fluctuations, the risk-hedging effect turns out to be independent of the number of firms too. In fact, when forward positions are not observable, the inverse hedge ratios are constant in the number of players:

$$
\hat{\Gamma}(\gamma=0)=1+\frac{1}{2}\left(\frac{1}{\frac{\rho \sigma^{2}}{b}}+\frac{1}{2+\frac{\rho \sigma^{2}}{b}}\right)
$$

When the forward market is not totally opaque so that the positions of the firms are somewhat observable, the strategic commitment role of selling forward leads firms to sell a higher output in the forward market the higher the number of players is. As a result, by the latter effect, inverse hedge ratios fall in $n$. When the market is fully transparent, in fact we obtain:

$$
\hat{\Gamma}(\gamma=1)=1+\frac{1+\frac{\rho \sigma^{2}}{b}}{n-1+(n+1) \frac{\rho \sigma^{2}}{b}+\left(\frac{\rho \sigma^{2}}{b}\right)^{2}}
$$


which clearly decreases in $n$.

We now take the new model to the data. We start by fitting the relation

$$
\frac{q_{t}}{x_{t}}=\frac{\gamma\left(n_{t}-1\right)+\left(n_{t}+1+\frac{\rho \sigma^{2}}{b}\right)\left(1+3 \frac{\rho \sigma^{2}}{b}+\left(\frac{\rho \sigma^{2}}{b}\right)^{2}\right)}{\left(2+\frac{\rho \sigma^{2}}{b}\right)\left(\gamma\left(n_{t}-1\right)+\frac{\rho \sigma^{2}}{b}\left(n_{t}+1+\frac{\rho \sigma^{2}}{b}\right)\right)}+\varepsilon_{t}
$$

where $\varepsilon_{t}$ is an error term. The NLS regression results are given in Table 5 . The results are similar in that the estimate for the observability parameter is relatively high and highly significant. The estimate for the risk aversion parameter is again non-significant. The relatively low $R^{2}$ indicates that this model does less well in explaining the observed variation in inverse hedge ratios than the model estimated in Section 3.3.

\begin{tabular}{ccc}
\hline \hline Parameter & Estimate & t-statistic \\
\hline$\lambda$ & 0.64 & 1.19 \\
$\gamma$ & $0.72^{*}$ & 5.98 \\
\hline$R^{2}=0.12$ & \\
\hline \hline
\end{tabular}

Table 5: NLS regression results; no proxy for $\sigma^{2}$

To control for variation in demand volatility, as before, we add the appropriate proxy. In this case, using the equilibrium equations we observe that $\sigma_{t}^{2}=\sigma_{p_{t}}^{2}$, so we just take the within-month variation in spot prices to proxy for the degree of demand uncertainty. The new estimates of equation (43) are given in Table 6. Again, controlling for month-to-month changes in demand volatility does not seriously affect the regression results; the estimate for $\gamma$ is still highly significant, while the estimate for $\lambda$ seems not to be able to explain any variation in the observed inverse hedge ratios.

\begin{tabular}{ccc}
\hline \hline Parameter & Estimate & t-statistic \\
\hline$\rho / b$ & 0.004 & 0.014 \\
$\gamma$ & $0.85^{*}$ & 15.41 \\
\hline$R^{2}=0.07$ & \\
\hline \hline & \\
\hline
\end{tabular}

Table 6: NLS regression with demand volatility measure

Finally, we look at the effects of including year dummies. The results are given in Table 7 . We see that the learning effect becomes less prominent than in the model we estimate in Section 3.3.

In sum, we conclude that our results in the main body of the paper are robust to this change in the modeling of the spot market. Irrespective of whether firms observe the demand shocks 


\begin{tabular}{ccc}
\hline \hline Parameter & Estimate & t-statistic \\
\hline$\rho / b$ & 0.002 & 0.004 \\
$\gamma_{2003}$ & $0.98^{*}$ & 8.22 \\
$\gamma_{2004}$ & $0.77^{*}$ & 3.81 \\
$\gamma_{2005}$ & $0.87^{*}$ & 8.21 \\
$\gamma_{2006}$ & $0.86^{*}$ & 8.50 \\
$\gamma_{2007}$ & $0.84^{*}$ & 8.83 \\
$\gamma_{2008}$ & $0.86^{*}$ & 8.46 \\
\hline$R^{2}=0.28$ & \multicolumn{2}{c}{} \\
\hline \multicolumn{2}{c}{ Notes: $n$ equal to wholesalers 80\% of market } \\
$*$ Significant at the 1 percent level
\end{tabular}

Table 7: NLS regression with demand volatility measure and year dummies.

before they supply gas in the spot market or not, we find that strategic considerations are important at explaining the observed hedge ratios in the industry. By contrast, risk-hedging appears not to have a large explanatory power. Comparing the fit of the two models to the data, we note that the model where spot strategies can be tuned to accommodate the demand shocks has a much higher explanatory power.

In Figure 7 we show the fit of the two models to the data, where we have used the estimates reported in Tables 3 and 6 to construct the fitted curves. Both models suggest that the forward market is rather transparent, as the two estimated curves predict a fall in the ratio of interest when more firms become active at the TTF. However, the model that does not allow firms to condition their spot strategies on the realized demand shock predicts a higher impact of firm entry on the inverse hedge ratio. This clearly gives a less good fit of the data, as can be concluded from comparing the $R^{2}$ of both regressions.

\subsection{Endogeneity of the number of wholesalers}

In our main model we have assumed demand is linear and this has implied that the relation to be estimated, equation (31), does not depend directly on the demand intercept parameter and the marginal cost of the firms. As a result, data on demand and costs are not essential to estimate equation (32) because changes in these variables are captured by changes in the forward sales. A related implication is that the estimates reported in Tables 2, 3 and 4 assume that the number of wholesalers is exogenous.

If, instead, we had used other demand specifications, the demand and cost parameters would probably have entered directly in the equilibrium condition we want to estimate. Omitting these variables, together with the fact that market profitability -and therefore the number of active wholesalers- at the TTF depends on market characteristics such as demand strength, the cost of supplying gas and the cost of entering the hub, raises the issue that the number

of active wholesalers is not exogenous from an econometrics point of view. To address 


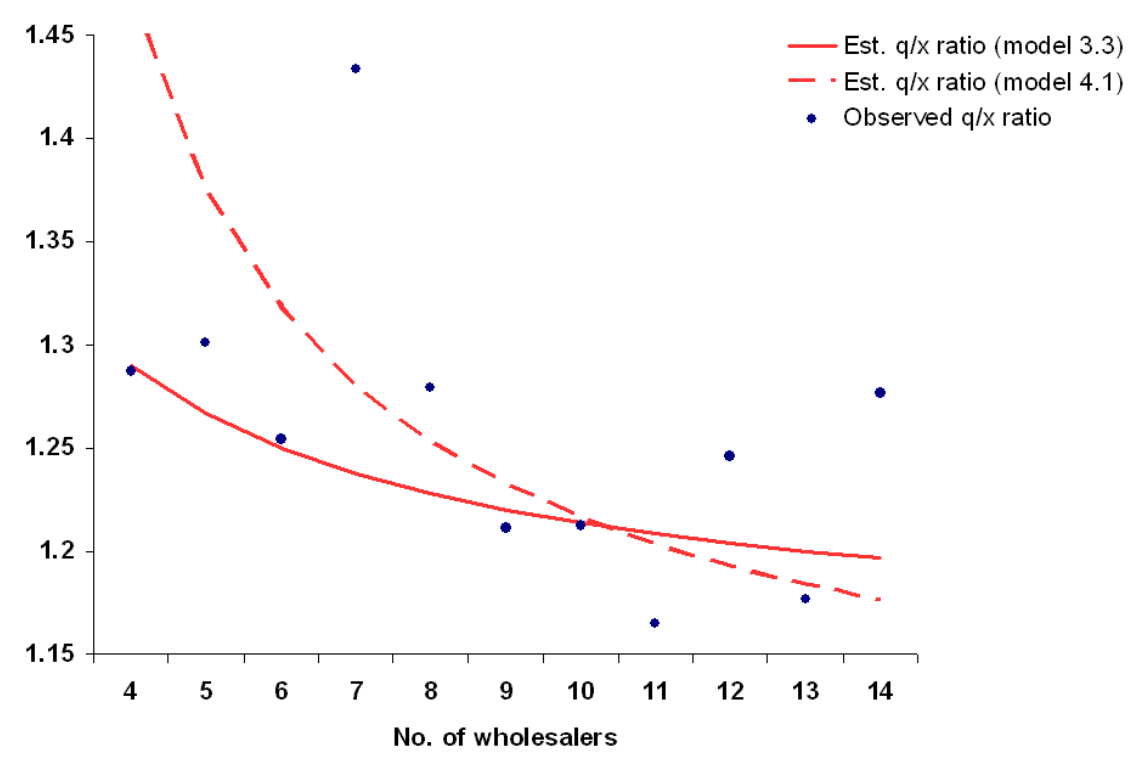

Figure 7: Fit of the different models

this potential endogeneity issue, we propose to use a free-entry condition that we estimate together with equation (32).

We assume that gas wholesalers enter the TTF till the last firm that enters makes zero profit in expectation. ${ }^{43}$ By substituting the equilibrium forward sales, given by equation (22), into the expression for profits we obtain the following zero-profit condition:

$$
(a-c)^{2} \Omega\left(b, \gamma, \rho, \sigma^{2}, n\right) / b-F+\nu=0, \quad \nu \sim N\left(0, \sigma_{\nu}^{2}\right)
$$

where $F$ denotes a firm's cost of entry, $\Omega=\omega_{1} \omega_{2}$, with

$$
\begin{aligned}
& \omega_{1}=\frac{(n+1-\gamma(n-1))\left((n+1)^{2}+2 \lambda\right)}{(n+1)^{2}} \\
& \omega_{2}=\frac{(n+1)^{2}(n+1+\gamma(n-1))+2(3(n+1)-\gamma(n-1)) \lambda}{\left((n+1)^{2}(n+1-\gamma(n-1))+2 \gamma n\left(n^{2}-1\right)+2(n(3-\gamma)+1+\gamma) \lambda\right)^{2}}
\end{aligned}
$$

and the term $\nu$ is a random shock normally distributed with mean equal to zero and standard deviation given by $\sigma_{\nu}$.

To add the information provided by the free entry condition (44) we need additional data. As a proxy for the demand intercept parameter $a$, we take monthly average prices of electricity

\footnotetext{
${ }^{43}$ While in our theoretical framework firms maximize expected utility once they have entered the market, we assume that firms base their entry decision on expected profits. A practical reason for doing this is that in case we let firm entry incentives be based on (expected) utility, the entry condition, which we are going to exploit in the estimation, becomes very cumbersome to deal with. One theoretical validation for the dissimilarity between firms' pre-entry and post-entry objectives is that market entry is decided upon by firm owners, who are typically assumed to be risk neutral, while daily control is delegated to firm managers, who are often considered as being risk-averse.
} 
spot contracts traded at the Dutch spot electricity exchange APX. In particular, we assume $a_{t}=a_{0}+a_{1} e_{t}$ where $a_{0}, a_{1}$ are free parameters and $e_{t}$ is the spot price of electricity in period $t .{ }^{44}$ On the cost side, we consider the oil price as being informative for the marginal production cost of a gas wholesaler. The rationale behind this is that prices in long-term contracts between gas producers and wholesalers are often indexed by the oil price. We therefore proxy the monthly marginal cost by $c_{t}=c_{0}+c_{1} o_{t}$, where $c_{0}, c_{1}$ are free cost parameters and $o_{t}$ is the monthly world oil price.

It is difficult to obtain information on entry costs. Wholesalers operating in the TTF have to pay a fixed fee of 1,263 Euros to register at the TTF for a single gas month. In addition, if these wholesale firms also want to participate in the centralized exchanges, they have to pay an extra fixed fee of 2083 Euros per month. ${ }^{45}$

We thus estimate the following system of equations:

$$
\left(\begin{array}{c}
y_{t} \\
0
\end{array}\right)=\left(\begin{array}{c}
g\left(n_{t}, \sum_{i=1}^{n} x_{i t}, \gamma, \sigma_{t}^{2}, \rho, b\right) \\
\xi r\left(a_{t}, c_{t}, F, n_{t}, \gamma, \sigma_{t}^{2}, \rho, b\right)
\end{array}\right)+\left(\begin{array}{c}
\epsilon_{t} \\
\xi \nu_{t}
\end{array}\right), \quad\left(\begin{array}{c}
\epsilon_{t} \\
\xi \nu_{t}
\end{array}\right) \sim\left(0,\left(\begin{array}{cc}
\sigma_{\epsilon_{t}}^{2} & 0 \\
0 & \sigma_{\nu}^{2}
\end{array}\right)\right)
$$

where

$$
\begin{aligned}
y_{t} & \equiv \frac{n_{t}+1}{n_{t}} \sum_{i=1}^{n} s_{i t} \\
g\left(n_{t}, \sum_{i=1}^{n} x_{i t}, \gamma, \sigma_{t}^{2}, \rho, b\right) & \equiv \frac{n_{t}+1}{n_{t}}\left(\Gamma\left(n_{t}, \gamma, \sigma_{t}^{2}, \rho, b\right)-1\right) \sum_{i=1}^{n} x_{i t} \\
r\left(a_{t}, c_{t}, F_{t}, n_{t}, \gamma, \sigma_{t}^{2}, \rho, b\right) & \equiv\left(d+a_{1} e_{t}-\beta_{1} c_{t}\right)^{2} \Omega\left(n_{t}, \gamma, \sigma_{t}^{2}, \rho, b\right)-F_{t}
\end{aligned}
$$

and $d=a_{0}-c_{0}$ and $\xi$ is a weighting parameter that is attached to the restrictions. Since the degree of informativeness of the zero-profit conditions depends on the variability of these restrictions, we set $\xi$ equal to the ratio of the standard deviations of the two error terms in (45), $\xi=\sigma_{\epsilon_{t}} / \sigma_{\nu} \cdot{ }^{46}$ The new regression results are summarized in Table 8.

The estimates of the key parameters do not change much if we include the stochastic zeroprofit conditions in the regressions. The strategic effect is again highly significant, while the risk-hedging motive is still non-significant.

\section{Concluding remarks}

This paper has proposed a methodology to investigate whether oligopolistic firms sell futures for strategic reasons, for risk-hedging motives, or for both. Our empirical test builds on a

\footnotetext{
${ }^{44}$ As mentioned above, a great deal of the gas traded in the TTF is high-calorific gas whose main use is in industrial applications such as the production of ammoniac as well as in the production of electricity.

${ }^{45}$ Next to the fixed fee, participants pay a variable tariff for each MWh traded in the TTF. These variable fees are picked up by the constant $c_{0}$ in our estimation.

${ }^{46}$ We conduct a feasible weighted NLS regression (see Greene, 1993, p. 209-211). The estimate of the weight $\xi$ is given by $\hat{\xi}=\sqrt{\frac{\hat{\epsilon}^{\prime} \hat{\epsilon}}{\hat{\nu}^{\prime} \hat{\nu}}}$, which is the square root of the ratio of the sums of squared residuals.
} 


\begin{tabular}{ccc}
\hline \hline Parameter & Estimate & t-statistic \\
\hline$\rho / b$ & $3.5 \cdot 10^{5}$ & 0.00 \\
$\gamma$ & $0.70^{*}$ & 43.52 \\
\hline$R^{2}=0.68$ & \\
\hline \hline Notes: $n$ equal to wholesalers $80 \%$ of market \\
* Significant at the 1 percent significance level
\end{tabular}

Table 8: NLS regression results with endogenous $n$

theoretical model of the interaction of risk-averse firms that compete in futures and spot markets. We find that the effects of an increase in the number of players on the equilibrium hedge ratio depend on the strategic role played by forward contracts. If forward sales play no strategic role whatsoever, the inverse hedge ratio increases as more firms enter the market; otherwise, the hedge ratio decreases. Firms hedge less if demand is very elastic and, as expected, more risk averse firms have a greater propensity to hedge. These results serve to structure our empirical research.

Using data from the Dutch wholesale market for natural gas where we observe the number of producers and wholesalers, forward and spot sales, and churn rates, we find evidence that strategic reasons play an important role at explaining the observed firms' hedge ratios. By contrast, the data do not support the idea that risk-hedging motives are an important aspect behind the observed firms' hedge ratios. Seen under the perspective that most of the forward transactions in the Dutch natural gas market occur OTC we think this is an important result. We also document a learning effect, which is probably related to the development of the market.

To increase transparency in the Dutch market for natural gas, the Dutch government did set up ENDEX, an exchange for natural gas futures. A complete cost-benefit analysis of ENDEX is outside the scope of this paper but our study suggests that the OTC market by itself provides the firms with sufficient incentives to sell forward. ${ }^{47}$

Futures markets exist for a number of commodities, including electricity, natural gas, emission trading permits, copper, iron ore, aluminium, steel etc. Though we have applied our model to the natural gas market in the Netherlands, we believe the general message of this paper is broader. Our insights, and in particular our methodology to address the question whether firms trade futures for strategic motives, should be applicable to other markets where firms have significant market power.

\footnotetext{
${ }^{47}$ The costs of operating a futures market are non-negligible even in a time where virtual market places have displaced the more traditional physical hubs. In fact, personnel and ICT costs, along with the insurance and financial costs of dealing with default and other risks involved may render a marketplace unprofitable. ENDEX has been making losses for 5 out of its 6 or 7 years of existence. At the end of 2009, ENDEX was taken over by the APX Group, which owns various platforms for spot trading of natural gas and electricity in the NL, Belgium and the UK.
} 


\section{Appendix}

\section{Appendix A: Proof of Proposition 1.}

It is clear that $\Gamma_{i}$ depends neither on $c_{i}$ nor on $a$. Given that

$$
\frac{\partial \Gamma_{i}}{\partial \rho_{i}}=-\frac{(n+1-\gamma(n-1))^{2} b \sigma^{2}}{\left(b \gamma\left(n^{2}-1\right)+2 \rho_{i} \sigma^{2}\right)^{2}}<0
$$

the inverse hedge ratio decreases as the firm is more risk averse. From this it readily follows that inverse hedge ratios decrease in the uncertainty of the demand parameter and increases in slope of the demand. Since

$$
\frac{\partial \Gamma_{i}}{\partial \gamma}=-\frac{(n-1)\left(b(n+1)^{2}+2 \rho_{i} \sigma^{2}\right)^{2}}{2(n+1)\left(b \gamma\left(n^{2}-1\right)+2 \rho_{i} \sigma^{2}\right)^{2}}<0
$$

the inverse hedge ratio decreases in the probability forward positions are observed.

Finally, we note that

$$
\frac{\partial \Gamma_{i}}{\partial n}=\frac{2 b(n+1)\left((n+1)^{2}+(n-1)^{2} \gamma^{2}-2 \gamma n(n+1)\right) \rho_{i} \sigma^{2}-b^{2} \gamma(n+1)^{4}-\left(2 \rho_{i} \sigma^{2}\right)^{2}}{(n+1)^{2}\left(b \gamma\left(n^{2}-1\right)+2 \rho_{i} \sigma^{2}\right)^{3}}
$$

Note that $\partial \Gamma_{i} / \partial n$ is differentiable w.r.t. $\gamma$, which implies that $\partial \Gamma_{i} / \partial n$ is continuous in $\gamma$.

Next, we observe that

$$
\left.\frac{\partial \Gamma_{i}}{\partial n}\right|_{\gamma=0}=\frac{b(n+1)}{2 \rho_{i} \sigma^{2}}>0
$$

and

$$
\left.\frac{\partial \Gamma_{i}}{\partial n}\right|_{\gamma=1}=-\frac{1}{(n+1)^{2}}-\frac{4 b^{2} n}{\left(b\left(n^{2}-1\right)+2 \rho_{i} \sigma^{2}\right)^{2}}<0
$$

for all $n \geq 2, b>0, \rho_{i}>0$ and $\sigma^{2}>0$. Given that $\partial \Gamma_{i} / \partial n$ is continuous in $\gamma$, this implies that $\partial \Gamma / \partial n=0$ for at least one $\gamma \in(0,1)$.

Further, $\partial \Gamma / \partial n=0$ has two solutions for $\gamma$, denoted by $\tilde{\gamma}$ and $\tilde{\gamma}_{2}$ :

$$
\tilde{\gamma} \equiv \frac{b^{2}(n+1)^{4}+4 b n(n+1)^{2} \rho_{i} \sigma^{2}+4 \rho_{i}^{2} \sigma^{4}-\left(b(n+1)^{2}+2 \rho_{i} \sigma^{2}\right) \sqrt{Z}}{4 b(n-1)^{2}(n+1) \rho_{i} \sigma^{2}}
$$

and

$$
\tilde{\gamma}_{2} \equiv \frac{b^{2}(n+1)^{4}+4 b n(n+1)^{2} \rho_{i} \sigma^{2}+4 \rho_{i}^{2} \sigma^{4}+\left(b(n+1)^{2}+2 \rho_{i} \sigma^{2}\right) \sqrt{Z}}{4 b(n-1)^{2}(n+1) \rho_{i} \sigma^{2}}
$$

where $Z=b^{2}(n+1)^{4}+4 b(n+1)^{2}(2 n-1) \rho_{i} \sigma^{2}+4 \rho_{i}^{2} \sigma^{4}$. Now for all $n \geq 2, b>0, \rho_{i}>0$ and $\sigma^{2}>0$, we have:

$$
\begin{aligned}
\tilde{\gamma}_{2}> & \frac{2\left(b(n+1)^{2}+2 \rho_{i} \sigma^{2}\right)^{2}+4 b(n-1)(n+1)^{2} \rho_{i} \sigma^{2}}{4 b(n-1)^{2}(n+1) \rho_{i} \sigma^{2}} \\
& >\frac{2\left(b(n+1)^{2}+2 \rho_{i} \sigma^{2}\right)^{2}+4 b(n-1)(n+1)^{2} \rho_{i} \sigma^{2}}{4 b n(n-1)(n+1) \rho_{i} \sigma^{2}} \\
& =\frac{n+1}{n}+\frac{\left(b(n+1)^{2}+2 \rho_{i} \sigma^{2}\right)^{2}}{2 b n(n-1)(n+1) \rho_{i} \sigma^{2}} \\
& >1
\end{aligned}
$$


Since $\tilde{\gamma}_{2}>1$ and $\partial \Gamma_{i} / \partial n=0$ for at least one $\gamma \in(0,1)$, it must be true that $\tilde{\gamma} \in(0,1)$. Now, because $\left.\frac{\partial \Gamma_{i}}{\partial n}\right|_{\gamma=0}>0$ and $\left.\frac{\partial \Gamma_{i}}{\partial n}\right|_{\gamma=1}<0$ and by continuity in $\gamma$, we have $\frac{\partial \Gamma_{i}}{\partial n}<0$ if $\gamma<\tilde{\gamma}$ and $\frac{\partial \Gamma_{i}}{\partial n}>0$ if $\gamma>\tilde{\gamma}$

Finally, imposing symmetry across firms we can readily obtain the equilibrium forward sales of a firm:

$$
\hat{x}=\frac{2(a-c)\left(n^{2}-1\right) \gamma+2 \frac{\rho \sigma^{2}}{b}}{(n+1)\left((n+1)^{2}+\gamma(n-1)^{2}+2(1+\gamma-n(\gamma-3)) \frac{\rho \sigma^{2}}{b}\right)}
$$

Observing the expression in equation 24, it is clear that the variance of the inverse hedge ratio is $\sigma^{2} / b^{2}(n+1)^{2} \hat{x}^{2}$, which clearly decreases in $a, \rho$ and $\sigma^{2}$, and increases in $c, b$ and in $\gamma$.

\section{Appendix B: TTF contracts}

All contracts traded in the TTF call for physical delivery of natural gas at the GTS transmission grid. Concerning forward transactions, the most prominent types of contracts are the ones that are also eligible at ENDEX:48

- Single-month contracts; these contracts can be traded from three months ahead till the expiration date, which is, with the exception of holidays, the penultimate working day of the month that precedes the month of delivery. The monthly contract then moves into delivery at the GTS transmission grid.

- Single-quarter contracts (quarters being defined as January-March, April-June, JulySeptember and October-December); trade in these contracts starts four quarters ahead and continues till the moment the contract expires. For this product, the day of expiration is the last but two working days of the last quarter before physical supply takes place. After expiration, the quarterly contract converts into three monthly contracts.

- Single-season contracts (seasons being defined as April-September and October-March); these contracts can change hands from four seasons ahead till the day of expiration, which is the last but two working days of the season preceding the delivery period. When the seasonal contract expires, it falls into three monthly contracts and one quarterly contract.

- Single-calendar-year contracts (calendar year being defined as January-December); these contracts can be traded from three calendar years ahead till the moment of

\footnotetext{
${ }^{48}$ There exist also some contracts that can be traded OTC but not in the centralized exchange ENDEX. Among them are the Balance-of-Month (BOM) and Working-Days-Next-Week (WDNW) contracts. These kind of forward products constitute only a tiny share of the total number of the transactions in the TTF.
} 
expiration, which is the last but two working days of the last year before the gas is delivered. After the contract expires, it cascades into three monthly contracts and three quarterly contracts.

The minimum volume that can be specified in quarterly, seasonal and calendar contracts is $10 \mathrm{MWh} / \mathrm{h}$; for monthly contracts, this minimum volume equals $30 \mathrm{MWh} / \mathrm{h}$.

Next to forward contracts, participants also trade spot contracts at TTF. Two types of spot market contracts can be distinguished:

- Day-ahead contracts; the trading market for these contracts opens two working days before physical supply takes place and closes two hours prior to the start of delivery.

- Within-day contracts; these contracts can be traded from 26 hours prior to delivery till two hours before the gas is physically supplied. 


\section{References}

[1] Allaz, B. (1992), "Oligopoly, Uncertainty and Strategic Forward Transactions," International Journal of Industrial Organization 10, 297-308.

[2] Allaz, B. and J.-L. Vila (1993), "Cournot Competition, Futures Markets and Efficiency," Journal of Economic Theory 59, 1-16.

[3] Anderson, E.J., X. Hu and D. Winchester (2007), "Forward Contracts in Electricity Markets," Energy Policy 35, 3089-3103.

[4] Asche, F., P. Osmundsen and R. Teveteràs (2002), "European Market Integration for Gas? Volume Flexibility and Political Risk," Energy Economics 24-3, 249-265.

[5] Ausubel L. M. and P. Cramton (2009), "Using Forward Markets to Improve Electricity Market Design," Working paper, University of Maryland.

[6] Bagwell, K. (1995), "Commitment and Observability in Games," Games and Economic Behavior 8, 271-280.

[7] Baron, D. P. (1970), "Price Uncertainty, Utility and Industry Equilibrium in Pure Competition," International Economic Review 11, 463-480.

[8] Bessembinder, H. and M. L. Lemmon (2002), "Equilibrium Pricing and Optimal Hedging in Electricity Forward Markets," Journal of Finance 57(3), 1347-1382.

[9] Borenstein, S. (2002), "The Trouble With Electricity Markets: Understanding California's Restructuring Disaster," Journal of Economic Perspectives 16(1), 191211.

[10] Bushnell, J.B. (2004), "Californias Electricity Crisis: a Market Apart?," Energy Policy $32,1045-1052$.

[11] Bushnell, J.B., E.T. Mansur and C. Saravia (2008), "Vertical Arrangements, Market Structure, and Competition: An Analysis of Restructured US Electricity Markets," American Economic Review 98(1), 237-66.

[12] Campa, J. M. and L. S. Goldberg (2005), "Exchange Rate Pass-Through into Import Prices," Review of Economics and Statistics 87(4), 679-690.

[13] Coq, C.L. and H. Orzen (2006), "Do forward markets enhance competition? Experimental evidence," Journal of Economic Behavior and Organization 61, 415-31.

[14] van Damme, E. and S. Hurkens (1997), "Games with Imperfectly Observable Commitment," Games and Economic Behavior, 21(1-2), 282-308.

[15] European Commission-EC (2007), DG Competition Report on Energy Sector Inquiry, SEC(2006), 1724, Brussels. 
[16] Fabra, N. and J. Toro (2005), "Price Wars and Collusion in the Spanish Eletricity Market," International Journal of Industrial Organization 23 (3-4), 155-81.

[17] Feder, G., R. E. Just and A. Schmitz (1980), "Futures Markets and the Theory of the Firm under Price Uncertainty," Quarterly Journal of Economics, 94, 17-328.

[18] Ferreira, J.L. (2003), "Strategic Interaction between Futures and Spot Markets," Journal of Economic Theory" 108, 141-151.

[19] Ferreira, J.L. (2006), "The Role of Observability in Futures Markets," Topics in Theoretical Economics 6-1, Article 7.

[20] Ferreira, J.L., P. Kujal and S. Rassenti (2009), "The Strategic Motive to Sell Forward: Experimental Evidence," Universidad Carlos III de Madrid, Working Paper 09-26, Economic Series (16).

[21] GTS (2008), Transport Insight 2008, Gas Transport Services B.V., The Netherlands.

[22] Green, R.J. (1999), "The Electricity Contract Market in England and Wales," Journal of Industrial Economics 47, 107-124.

[23] Greene, W.H. (1993), Econometric Analysis, Prentice Hall.

[24] Hortaçsu, A. and S.L. Puller (2008), "Understanding Strategic Bidding in Multi-Unit Auctions: a Case Study of the Texas Electricity Spot Market," Rand Journal of Economics 39(1), 86-114.

[25] Holthausen, D.M. (1979), "Hedging and the Competitive Firm Under Price Uncertainty," American Economic Review 69, 987-995.

[26] Hughes, J.S. and J.L. Kao (1997), "Strategic Forward Contracting and Observability," International Journal of Industrial Organization 16, 121-133.

[27] Katz, E. (1984), "The Firm and Price Hedging in an Imperfect Market," International Economic Review 25, 215-219.

[28] Liski, M. and J.-P. Montero (2006), "Forward Trading and Collusion in Oligopoly," Journal of Economic Theory 131, 212-230.

[29] Longstaff, F.A. and A.W. Wang (2004), "Electricity Forward Prices: A High-Frequency Empirical Analysis," Journal of Finance 59, 1877-1900.

[30] Mahenc, P. and F. Salanié (2004), "Softening Competition through Forward Trading," Journal of Economic Theory 116, 282-293.

[31] Masten, S.E. and K.J. Crocker (1985), "Efficient Adaptation in Long-Term Contracts: Take-or-Pay Provisions for Natural Gas," American Economic Review 75, 1083-1093. 
[32] Newbery, D.M. (1998), "Competition, Contracts, and Entry in the Electricity Spot Market," The RAND Journal of Economics 29, 726-749.

[33] NMa/DTe (2007), "Versnelling van de Ontwikkeling van TTF en de Groothandelsmarkt voor Gas.

[34] IEA (2002), Flexibility in Natural Gas Supply and Demand, Paris: OECD.

[35] Powell, A. (1993), "Trading Forward in an Imperfect Market: The Case of Electricity in Britain," Economic Journal 103, 444-453.

[36] Sandmo, A. (1971), "On the Theory of the Competitive Firm under Price Uncertainty," American Economic Review 61, 65-73.

[37] Tirole, J. (2006), The Theory of Corporate Finance, Princeton University Press.

[38] von der Fehr, N-H. M. and D. Harbord (1992), "Long-term Contracts and Imperfectly Competitive Spot Markets: A Study of the UK Electricity Industry," Memorandum no. 14, Department of Economics, University of Oslo.

[39] von der Fehr, N-H. M and P. V. Hansen (2010), "Eletricity Retailing in Norway," The Energy Journal, 31(1), 25-45.

[40] Wolak, F. A. (2000), "An Empirical Analysis of the Impact of Hedge Contracts on Bidding Behavior in a Competitive Electricity Market," International Economic Journal 14(2), 1-39. 